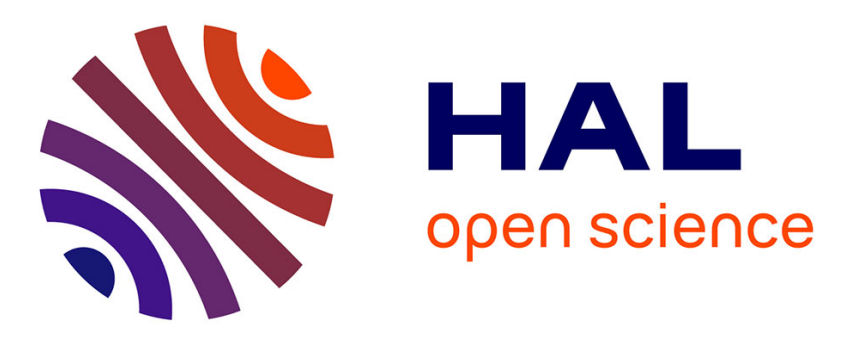

\title{
Direct sintering of UO2+x oxides prepared under hydrothermal conditions
}

J. Manaud, Renaud Podor, X. F Le Goff, Jérôme Maynadie, Nicolas Dacheux, Nicolas Clavier

\section{- To cite this version:}

J. Manaud, Renaud Podor, X. F Le Goff, Jérôme Maynadie, Nicolas Dacheux, et al.. Direct sintering of UO2+x oxides prepared under hydrothermal conditions. Journal of the European Ceramic Society, 2021, 41 (13), pp.6697-6707. 10.1016/j.jeurceramsoc.2021.06.006 . hal-03259275

\section{HAL Id: hal-03259275 \\ https://hal.science/hal-03259275}

Submitted on 14 Jun 2021

HAL is a multi-disciplinary open access archive for the deposit and dissemination of scientific research documents, whether they are published or not. The documents may come from teaching and research institutions in France or abroad, or from public or private research centers.
L'archive ouverte pluridisciplinaire HAL, est destinée au dépôt et à la diffusion de documents scientifiques de niveau recherche, publiés ou non, émanant des établissements d'enseignement et de recherche français ou étrangers, des laboratoires publics ou privés. 


\title{
Direct sintering of $\mathrm{UO}_{2+\mathrm{x}}$ oxides prepared under hydrothermal conditions
}

\author{
Jérémie Manaud ${ }^{1}$, Renaud Podor ${ }^{1}$, Xavier F. Le Goff ${ }^{1}$, Jérôme Maynadié ${ }^{1}$, \\ Nicolas Dacheux ${ }^{1}$, Nicolas Clavier ${ }^{1, *}$
}

1 ICSM, Univ Montpellier, CNRS, ENSCM, CEA, Bagnols-sur-Cèze, France

\footnotetext{
* Corresponding author:
}

Dr. Nicolas CLAVIER

ICSM, Univ Montpellier, CNRS, CEA, ENSCM

Site de Marcoule

BP 17171

30207 Bagnols sur Cèze

France

Phone : + 33466339208

Fax : + 33466797611

nicolas.clavier@icsm.fr 


\begin{abstract}
:
The sintering of uranium oxide powders prepared by hydrothermal conversion of oxalates was studied. A dilatometric study first showed that among the synthesis conditions, only the $\mathrm{pH}$ largely impacted the densification, notably through the powders morphology. Three samples ( single crystals $-\mathrm{pH}=1$, microspheres $-\mathrm{pH}=2$ and nano- powders $-\mathrm{pH}=8$ ) were further selected to study their sintering behaviour. Densitometric and granulometric data then allowed establishing sintering maps. For single crystals and microspheres, densities above 96\%TD were obtained at $1700^{\circ} \mathrm{C}$. In contrast, only 2 to 8 hours at $1500^{\circ} \mathrm{C}$ were needed to yield comparable results for nano-powders. These observations confirm that the hydrothermal conversion of oxalates can be considered as a promising route for the synthesis of actinide oxides, which can subsequently be sintered directly.
\end{abstract}

\title{
Keywords:
}

Uranium oxide, Hydrothermal synthesis, Dilatometry, Sintering map, Microstructure 


\section{Introduction}

Already commonly used in light water nuclear reactors worldwide, uranium $\left(\mathrm{UO}_{2}\right)$ and uranium-plutonium dioxides $\left((\mathrm{U}, \mathrm{Pu}) \mathrm{O}_{2}\right.$, also known as $\left.\mathrm{MOx}\right)$ are also envisaged as reference fuels for future generations of fast neutron reactors, such as SFR (Sodium-cooled Fast Reactor) [1], [2]. Beyond the opportunities offered by such reactors, including the possibility to transmute minor actinides [3] or to co-generate dihydrogen using residual heat [4], the transition from thermal to fast neutron spectra will allow to rethink plutonium management within the fuel cycle. First, while the amount of plutonium is generally limited around 7-10 wt.\% in current MOx assemblies, it could be enhanced up to $30 \mathrm{wt} . \%$, thus limiting plutonium stockpile [2]. Also, multi-recycling MOx is envisaged to close the fuel cycle [5]. In order to face these technological challenges, the manufacturing of the fuel ceramic has to be optimized. Especially, homogeneous mixed oxides should be favoured to prevent the existence of Pu-enriched hot spots during in-core lifetime, that can also become refractory towards dissolution during the reprocessing step [6]. On this basis, if processes based on powder metallurgy have been studied for long (for example with the COCA process in France) [7], numerous studies also considered wet chemistry methods to precipitate homogeneous precursors (i.e. solid solutions) starting from ions in solution [8].

Among the various complexing agents investigated to co-precipitate cations mixtures, oxalates dragged important attention, mainly due to their rich crystal chemistry which allows the incorporation of actinides with different redox states (e.g. $\mathrm{U}(\mathrm{IV})$ and $\mathrm{Pu}(\mathrm{III})$ ) within a unique structural lattice [9]. The final oxide is further obtained after a heat treatment at high temperature (typically from 700 to $1000^{\circ} \mathrm{C}$ ) under controlled atmosphere, called thermal conversion [10], [11]. Although very convenient, and already used industrially to recover plutonium after $\mathrm{UO}_{2}$ spent fuel reprocessing, oxalic conversion still presents some limitations. First, the precipitation of An(IV) oxalates is generally associated to a square-shaped platelets habit that is further retained within the oxide powder [12]. This morphological feature can limit the powder flowability when shaping pellets for ceramic fabrication, and then induce some mechanical defects after sintering. Also, oxide based powders coming from oxalate precursors generally incorporate residual traces of carbon, typically from around 100 ppm when calcined under air [13] up to several thousands of ppm for thermal conversion performed under inert or reducing atmosphere [12], which have been associated to dedensification processes [14], [15]. 
To prevent these drawbacks, and provide a more direct route from ions in solutions to mixed dioxides, several authors recently investigated the use of mild hydrothermal conditions to operate the conversion of An(IV) oxalate towards final oxides [16]-[19]. In the case of uranium-based compounds, the temperature considered for hydrothermal treatment typically ranged between 180 and $250^{\circ} \mathrm{C}$, while duration can be as short as 1 hour and go up to 1 to several days. The oxides produced by these means were systematically found to crystallize into the classical fluorite-type structure of $\mathrm{UO}_{2+\mathrm{x}}$, and to present low contents in impurities such as water and carbon. Also, tuning the $\mathrm{pH}$ of the precipitation media was found to deeply modify the morphology of the final powder [19]. All these findings pave the way to the direct sintering of the raw oxides obtained after hydrothermal treatment of the oxalate precursor, which would offer a compact process going from ions in solution to fuel pellet in few steps only. In this field, authors already demonstrated that dense pellets with limited coarsening (0.2 - $5.5 \mu \mathrm{m}$ grains) can be obtained by using SPS [20], [21]. However, the sintering ability of uranium oxide powders obtained by hydrothermal conversion of oxalates has never been tested for natural sintering. In this aim, the present work first consisted in the dilatometric study of an exhaustive set of $\mathrm{UO}_{2+x}$ samples obtained in various conditions of hydrothermal treatment. Once the main factors of influence established, three representative powders were selected to build sintering maps and link the conditions of synthesis with the final microstructure of the ceramics. Finally, first results regarding the grain growth mechanisms and the associated activation energy are also reported herein. 


\section{Material and methods}

\subsection{Preparation of the samples and pelletization}

All the samples studied in this work were prepared by conversion of uranium(IV) oxalate, $\mathrm{U}\left(\mathrm{C}_{2} \mathrm{O}_{4}\right)_{2} \cdot 6 \mathrm{H}_{2} \mathrm{O}$, into $\mathrm{UO}_{2+\mathrm{x}} \cdot \mathrm{nH}_{2} \mathrm{O}$ oxide samples under mild hydrothermal conditions, following the protocol reported in our previous work [19]. Oxalate precursor precipitation was carried out by mixing hydrochloric solution containing U(IV) with oxalic acid. Both the solid phase and the supernatant were further transferred in a Parr Teflon-lined autoclave. The volume was then adjusted to $15 \mathrm{~mL}$ by adding diluted $\mathrm{HCl}$ or $\mathrm{NH}_{4} \mathrm{OH}$, which also led to control the $\mathrm{pH}$ value between 0.5 and 10 . The reactor was finally sealed then heated at $190-250^{\circ} \mathrm{C}$ for 1 to 48 hours. In these conditions, the maximum autogenous pressure was estimated to about 80 bars [22].

After the hydrothermal treatment, the resulting precipitate was separated by centrifugation at $14000 \mathrm{rpm}$, washed twice with deionized water and twice with ethanol then finally dried overnight at $90^{\circ} \mathrm{C}$. All the samples prepared in the experimental conditions summarized in Table 1 were extensively characterized in our previously published paper [19] and were found to consist in $\mathrm{UO}_{2+\mathrm{x}}$ oxides.

The powders were further directly pelletized at room temperature using a uniaxial press $(\mathrm{P}=500 \mathrm{MPa})$ and a $5 \mathrm{~mm}$ diameter tungsten carbide die, without any additional treatment such as grinding step. Zinc stearate was used as an external lubricant. The obtained pellets weighed about $200 \mathrm{mg}$, with a thickness ranging from 1.2 to $1.9 \mathrm{~mm}$. This corresponded to green density values ranging from $52 \%$ to $67 \%$ of the theoretical density (TD) of $\mathrm{UO}_{2}\left(10.97 \mathrm{~g} . \mathrm{cm}^{-3}\right)$ (Table 1). 
Table 1. Geometric density of pellets after thermal treatment at $1600^{\circ} \mathrm{C}$ (without any dwell) related to experimental conditions of preparation of powders. Uncertainty on the density values: $\pm 1 \%$. Star and triangle symbols refer to the dilatometric curves reported in Figure 2.

\begin{tabular}{|c|c|c|c|c|}
\hline Temperature $\left({ }^{\circ} \mathbf{C}\right)$ & $\overline{\text { Duration (h) }}$ & Initial pH & Green density (\%) & Sintered density (\%) \\
\hline 190 & \multirow{11}{*}{24} & \multirow{6}{*}{$<1$} & 54 & 91 \\
\hline 210 & & & 57 & 91 \\
\hline 220 & & & 56 & 90 \\
\hline 230 & & & 63 & 92 \\
\hline 240 & & & 61 & 92 \\
\hline \multirow{11}{*}{250} & & & 66 & $93 \star$ \\
\hline & & 1 & 67 & 93 \\
\hline & & 2 & 53 & 85 \\
\hline & & 6 & 58 & 95 \\
\hline & & 8 & 53 & 95 \\
\hline & & 10 & 52 & 96 \\
\hline & 1 & \multirow{5}{*}{5} & 52 & 84 \\
\hline & 5 & & 56 & 94 \\
\hline & 15 & & 55 & 84 \\
\hline & 24 & & 56 & $84 \boldsymbol{\Lambda}$ \\
\hline & 48 & & 55 & 85 \\
\hline
\end{tabular}

\subsection{Density measurements}

The geometrical density of green and sintered samples (Table 1) was determined by measurements of pellets thickness and diameter using a precision calliper. This value led to an estimation of the global porosity within the samples. In parallel, relative densities were determined by helium pycnometry measurements (Micromeritics Accupyc 1340) which account for the contribution of closed porosity. Open and closed porosities were then determined thanks to the results obtained through these two complementary techniques. $1 \%$ of uncertainty was systematically considered for density values (Table 1). This came from the precision of the calliper used and from the geometrical defects of the pellets, on the one hand, and from the small amount of sample analysed by He-pycnometry, on the other. 


\subsection{Specific Surface Area}

The Specific Surface Area $\left(\mathrm{S}_{\mathrm{SA}}\right)$ of the synthesized powders was determined using a Micrometric ASAP 2020 apparatus with BET method (nitrogen adsorption at $77 \mathrm{~K}$ ).

\subsection{Dilatometry}

Dilatometric measurements were conducted on a Setaram Setsys Evolution apparatus. All the pellets were placed between two alumina plates to avoid contamination of the sample environment, then heated up to $1600^{\circ} \mathrm{C}$ under $\mathrm{Ar} / \mathrm{H}_{2} 4 \%$ considering a heating rate of $2^{\circ} \mathrm{C} \cdot \mathrm{min}^{-1}$. Natural cooling was further operated down to room temperature.

\subsection{Sintering}

Pellets were sintered in tungsten boats between 1500 and $1700^{\circ} \mathrm{C}$ for $1-8 \mathrm{~h}$ under $\mathrm{Ar} / \mathrm{H}_{2} 4 \%$ atmosphere using a tubular $\left(1500^{\circ} \mathrm{C}\right)$ or a muffle furnace (AET technologies) (1600 $\left.-1700^{\circ} \mathrm{C}\right)$. A heating rate of $2^{\circ} \mathrm{C} \cdot \mathrm{min}^{-1}$ was applied and a natural cooling was used down to room temperature.

\subsection{Grain size determination}

The determination of average grains size was performed using the SEraMic method reported by Podor et al. [23], and based on the recording and the processing of series of SEM images in backscattered electron mode (BSE). Samples were first polished to a mirror grade, then SEM observations were conducted with a FEI Quanta 200 ESEM FEG microscope without any additional sample surface treatment such as chemical or thermal etching. Images were recorded in the BSE mode using a CBS detector (Concentric BackScattered detector) purchased from FEI. BSE images were recorded at $3 \mathrm{kV}$, under high vacuum and at low probe current, resulting in a crystallographic orientation contrast. By changing the angle of inclination of the surface of the sample relative to the incident electron beam by a few degrees, this contrast was altered and the same area of the specimen was represented with different grey levels (Figure 1). Recording several images at different angles then allowed us to reveal all the grains present at the surface of the sample. 

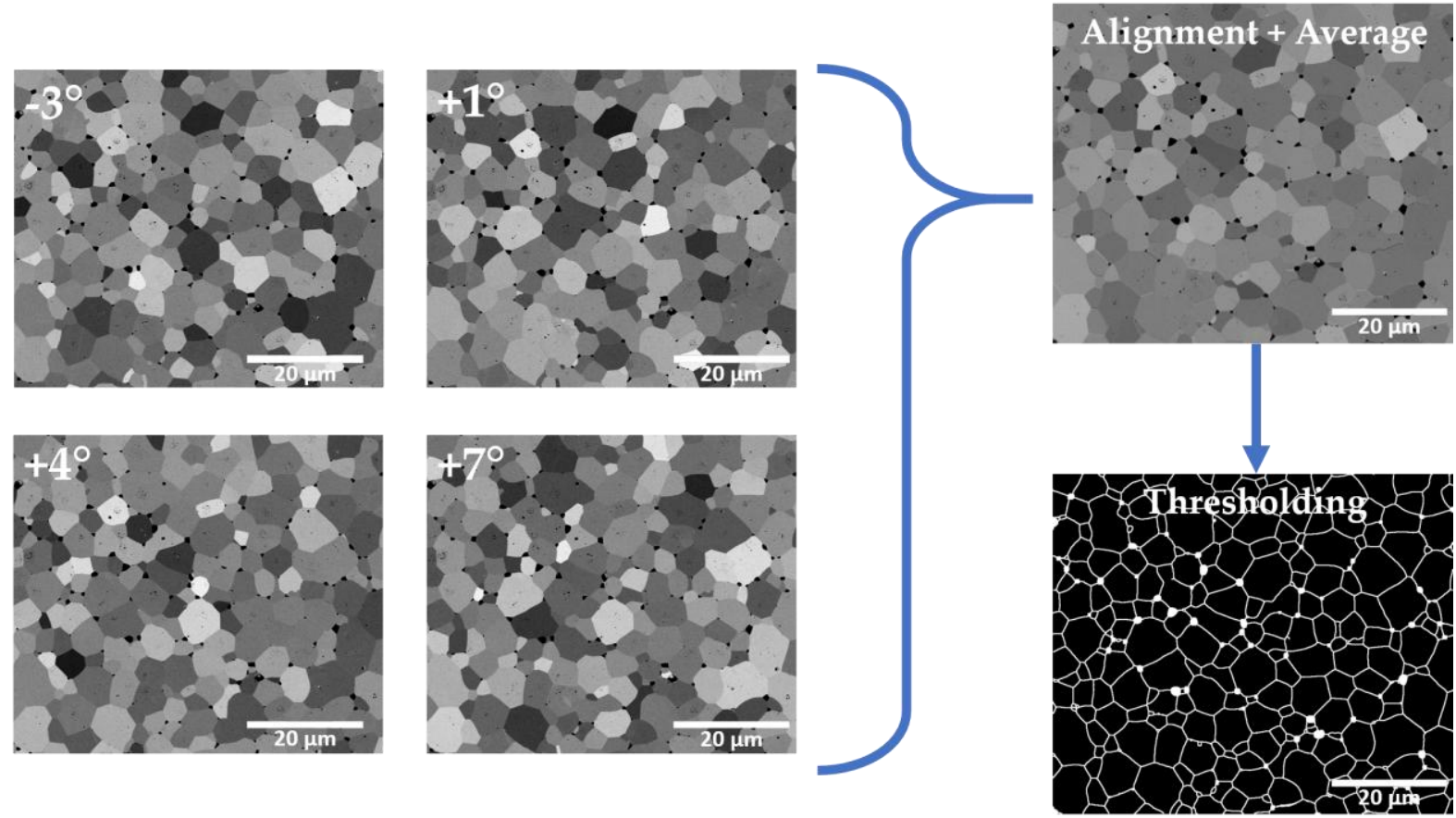

Figure 1. Image processing using the SEraMic plugin for a polished $\mathrm{UO}_{2}$ pellet sintered at $1600^{\circ} \mathrm{C}$ for 1 hour. The white lines represent the grain boundaries while white dots account for the pores. 178 grains were analysed in this area.

Each series of images was processed using the SEraMic plugin implemented in the Fiji image analysis software [24]. The images were aligned and then the grain outlines and pores were automatically identified. After correcting the defects mainly caused by residual polishing scratches, a binarized image representing the grains in black and the grain boundaries in white was obtained using a threshold function.

Excluding incomplete grains located at the periphery of the images, the surface A of each grain was determined using the "Particles Analysis" function of the Fiji software. On this basis, the equivalent diameter $\mathrm{D}$ has been calculated as follows:

$D=2 \cdot(A / \pi)^{1 / 2}$

Typically, 500 to 1000 grains were considered for each sample, which allowed us to access granulometric distribution with satisfactory counting statistics. 


\section{Results and Discussion}

\subsection{Dilatometric study}

The variation of the relative linear shrinkage of the uranium oxide pellets as a function of the synthesis parameters (i.e. temperature, duration of hydrothermal treatment and $\mathrm{pH}$ of the initial mixture) is shown in Figure 2. The shrinkage of pellets prepared from powders synthesized at different temperatures (Figure 2a) is always very similar, except for the powder obtained at $250^{\circ} \mathrm{C}$. Powders obtained for $190^{\circ} \mathrm{C} \leq \mathrm{T} \leq 240^{\circ} \mathrm{C}$ showed two successive shrinkage steps, the first around $1000^{\circ} \mathrm{C}$ and the second at $1300^{\circ} \mathrm{C}$. They probably correspond to intra-agglomerate densification (aggregate of crystallites) with a departure of water and carbon, then to inter-agglomerate densification as described by Martinez et al. when working with powders prepared from the thermal conversion of uranium(IV) oxalate [12]. Similarly, the maximum shrinkage rate systematically reached around $1500^{\circ} \mathrm{C}$. Nevertheless, no plateau showing the end of sintering was reached, meaning that complete densification requires temperatures above $1600^{\circ} \mathrm{C}$ (maximum running temperature of the dilatometer used) or longer holding times. Conversely, the powder obtained at $250^{\circ} \mathrm{C}$ only exhibited one shrinkage step between $800^{\circ} \mathrm{C}$ and $1500^{\circ} \mathrm{C}$, corresponding to the sintering of the pellet. This difference can be explained by the presence of smaller crystallites which react more quickly to sintering [19]. Above $1500^{\circ} \mathrm{C}$, a phenomenon of de-densification, sometimes called "solarisation", was also observed, which could have been be caused by coalescence of pores or exaggerated grain growth [15], [25]-[28]. 
a)

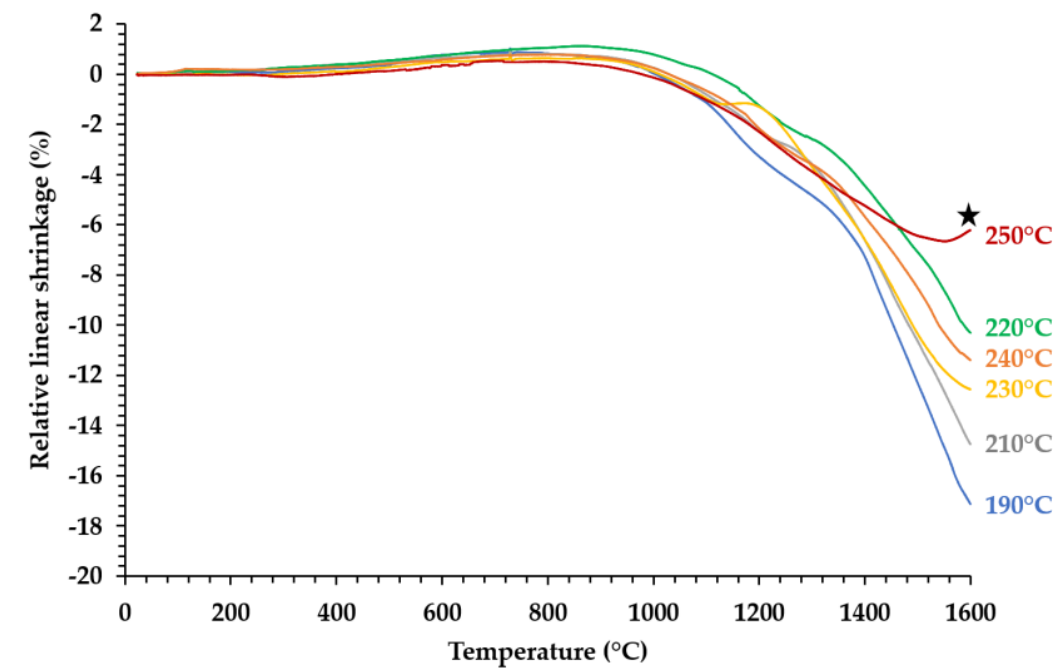

b)

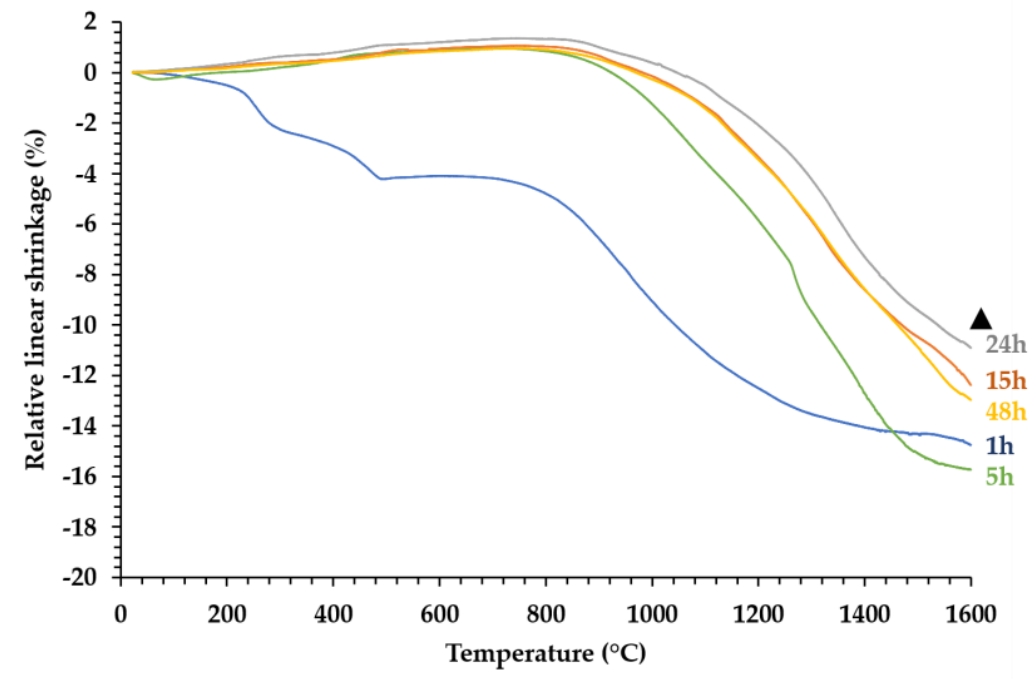

c)

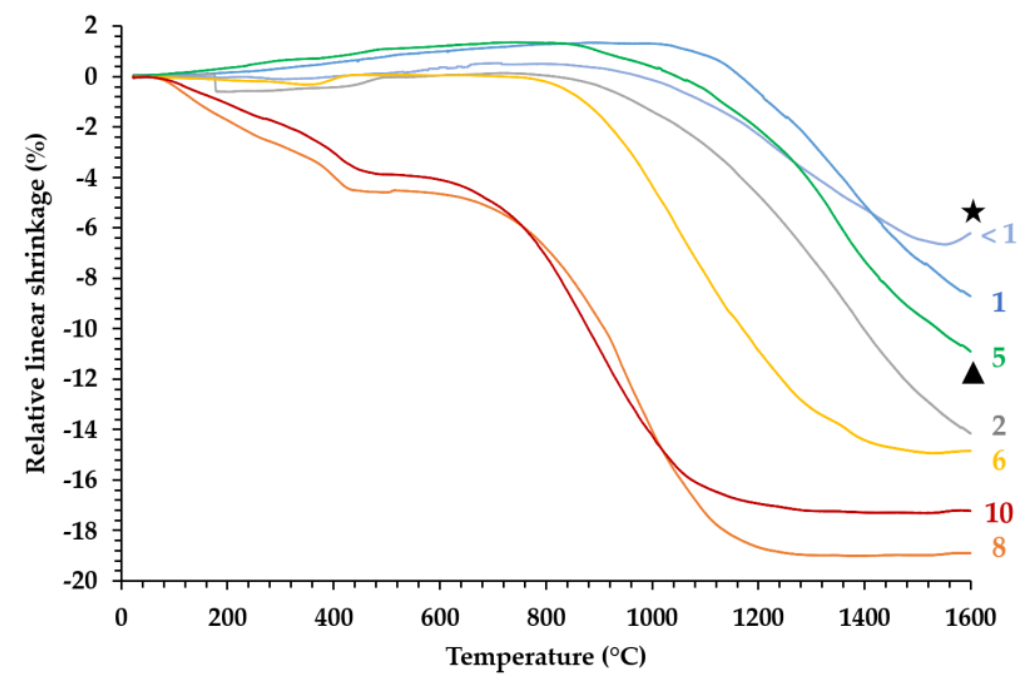

Figure 2. Relative linear shrinkage of uranium oxide pellets as a function of a) synthesis temperature $(24 \mathrm{~h}-\mathrm{pH}<1)$, b) hydrothermal treatment duration $\left(250^{\circ} \mathrm{C}-\mathrm{pH}=\right.$ 5) and c) $\mathrm{pH}$ of the initial solution $\left(250^{\circ} \mathrm{C}-24 \mathrm{~h}\right)$. Star and triangle symbols represent identical samples on the different figures (see synthesis conditions and densities in Table 1). 
When varying the hydrothermal treatment duration at $250^{\circ} \mathrm{C}(\mathrm{pH}=5)$, two different shrinkage profiles were observed (Figure $2 \mathbf{b}$ ). For $\mathrm{t}=1 \mathrm{~h}$, a complex densification behaviour was noted, with three distinct steps. The first two, up to $300^{\circ} \mathrm{C}$, then to $500^{\circ} \mathrm{C}$, each corresponding to a $2 \%$ shrinkage, could be associated to the impurities (water molecules and residual carbon) content reported in our previous work [19]. Thus, the first two shrinkages probably correspond to the successive elimination of water (with initially 0.65 mole of water per mole of uranium) and then of residual carbon ( $1 \mathrm{wt} . \%)$. In the same time, one must keep in mind that reduction of $\mathrm{U}(\mathrm{V}) / \mathrm{U}(\mathrm{VI})$ to $\mathrm{U}(\mathrm{IV})$ occurs, corresponding to the transformation of $\mathrm{UO}_{2+\mathrm{x}}$ into $\mathrm{UO}_{2.00}$. Although it is known to induce to a slight lattice expansion, this feature cannot be observed here due to the elimination of volatile species. The third step of shrinkage (11\%) corresponds to the densification of the pellet. For powders synthesised using longer hydrothermal treatment durations $(5 \mathrm{~h}-48 \mathrm{~h})$, the shrinkage curves are similar. They all show a slight expansion up to $800^{\circ} \mathrm{C}$ followed by a single shrinkage step up to $1600^{\circ} \mathrm{C}$. This simplification of the shrinkage profile fits well with the decrease of carbon and water amounts in the powders prepared after at least 5 hours of hydrothermal treatment [19]. For these samples, a maximum shrinkage rate is then reached at around $1430^{\circ} \mathrm{C}$.

Finally, the shrinkage curves obtained for samples synthesised at various $\mathrm{pH}$ showed the most important differences (Figure 2c). All the powders prepared for $\mathrm{pH} \leq 6$ presented similar profiles but differed essentially in the temperature of maximum shrinkage rate. This latter decreased from $1430^{\circ} \mathrm{C}, 1385^{\circ} \mathrm{C}, 1330^{\circ} \mathrm{C}$ down to $1150^{\circ} \mathrm{C}$ for $\mathrm{pH}<1, \mathrm{pH}=1,2$ and 6 , respectively. Among these samples, only the one obtained at $\mathrm{pH}=6$ led to a plateau indicating a complete densification. For powders prepared at $\mathrm{pH}<1$, a de-densification step was even observed above $1500^{\circ} \mathrm{C}$ [15], [28]. In contrast, powders synthesised at $\mathrm{pH}=8$ and 10 presented a distinct profile with a first shrinkage step of $4-5 \%$ up to $400^{\circ} \mathrm{C}$ and a second one of $12-14 \%$ up to $1150^{\circ} \mathrm{C}$, which ended with a plateau. They were assigned to the removal of organic species trapped in the pellet then to the sintering step which took place for a much lower temperature compared to all the other samples studied. Such a specific behaviour, as well as the presence of organics, can be explained by the higher surface area of the powders obtained at high $\mathrm{pH}$ (i.e. 8 or 10) [19].

In addition to this dilatometric study, geometrical density measurements were carried out for all the pellets submitted to heat treatment up to $1600^{\circ} \mathrm{C}$ (Table 1). The obtained values confirmed the low impact of the temperature and duration of the hydrothermal conversion on the sinterability of the oxide powders. Indeed, they remained close to $92 \%$ TD whatever the hydrothermal conversion temperature at $\mathrm{pH}<1$. Similarly, relative densities close to $84 \% \mathrm{TD}$ 
were determined for all powders prepared at $\mathrm{pH}=5$ and $\mathrm{T}=250^{\circ} \mathrm{C}$, regardless of the conversion duration. All these values confirmed that the densification of the pellets was not complete, and therefore requires temperatures higher than $1600^{\circ} \mathrm{C}$ or longer holding times.

Furthermore, the $\mathrm{pH}$ of the initial solution used during the hydrothermal conversion process appeared as the main parameter significantly modifying the sintering profile of the oxide powders prepared. Also, low density values, close to $85 \%$, were reached for powders prepared at $\mathrm{pH}=2$ and 5, while higher densities (93-96\%) were measured for other $\mathrm{pH}$ values. As such, the morphology of the powders, which was strongly modified by the $\mathrm{pH}$ conditions, seems to be the main parameter which could explain these variations.

\subsection{Sintering study}

\subsubsection{Selection of samples and operating conditions}

According to the results of the dilatometric study, the $\mathrm{pH}$ of the initial solution was found to be the experimental variable causing the greatest variation in the sintering behaviour of the powders. These differences mostly arose from the samples morphology which effect should be examined in details. In this purpose, three uranium-based oxide samples prepared at $250^{\circ} \mathrm{C}$ for 24 hours at different $\mathrm{pH}$ were selected. Their main characteristics, extracted from our previous work [19], are summarized in Table 2.

Table 2. Physico-chemical properties of uranium oxide powders prepared at $250^{\circ} \mathrm{C}$ for 24 hours and various starting $\mathrm{pH}$ conditions.

\begin{tabular}{cccccccc}
\hline $\mathbf{p H}$ & $\begin{array}{c}\text { Average } \\
\text { crystallites } \\
\text { size } \\
(\mathbf{n m})\end{array}$ & $\begin{array}{c}\text { Specific } \\
\text { surface } \\
\mathbf{a r e a} \\
\left(\mathbf{m}^{\mathbf{2}} \cdot \mathbf{g}^{-1}\right)\end{array}$ & Morphology & $\begin{array}{c}\text { Residual } \\
\text { carbon } \\
\text { content } \\
(\boldsymbol{\%} \text { mass. })\end{array}$ & $\begin{array}{c}\text { Hydration } \\
\text { rate } \\
\left(\mathbf{m o l .} \mathbf{H}_{\mathbf{2}} \mathbf{O} /\right. \\
\mathbf{U})\end{array}$ & $\begin{array}{c}\text { O/U ratio } \\
\text { range }\end{array}$ & $\begin{array}{c}\text { Average } \\
\text { green } \\
\text { density } \\
(\boldsymbol{\%})\end{array}$ \\
\hline 1 & $80-110$ & $2.6 \pm 0.1$ & $\begin{array}{c}\text { Single } \\
\text { crystals }\end{array}$ & $<0.01$ & $<0.01$ & $2.00-2.05$ & $56.2 \pm 1.2$ \\
\hline 2 & $20-30$ & $14.5 \pm 0.1$ & Microspheres & $0.09 \pm 0.02$ & $0.17 \pm 0.01$ & $2.20-2.25$ & $48.1 \pm 1.3$ \\
\hline 8 & 10 & $29.9 \pm 0.1$ & $\begin{array}{c}\text { Nano- } \\
\text { powders }\end{array}$ & $0.07 \pm 0.02$ & $0.38 \pm 0.01$ & $2.20-2.25$ & $52.6 \pm 1.2$ \\
\hline
\end{tabular}

The sample synthesised at $\mathrm{pH}=1$ was composed of polyhedral grains ranging from $100 \mathrm{~nm}$ to almost $1 \mu \mathrm{m}$ in length. This size lies in the same order of magnitude than that of the average crystallite sizes determined from Rietveld refinement of XRD data, meaning that 
most of the particles can be considered as single crystals. As a consequence, the associated specific surface area was found to be very low, i.e. $2.6 \pm 0.1 \mathrm{~m}^{2} \cdot \mathrm{g}^{-1}$ (Figure 3). At $\mathrm{pH}=2$, the powders were found to be mainly composed of polydisperse spherical particles of $500 \mathrm{~nm}$ to 5 $\mu \mathrm{m}$ in diameter. Similar particles were already described during the hydrothermal treatment of other uranium(IV) carboxylates in a comparable range of $\mathrm{pH}$ [29]. They were composed by smaller crystallites of 20-30 $\mathrm{nm}$ and still bore an important porosity, which led to a specific surface area of $14.5 \pm 0.1 \mathrm{~m}^{2} \cdot \mathrm{g}^{-1}$. Finally, the powder prepared at $\mathrm{pH}=8$ appeared in the form of loose nanoparticles of approximately $10 \mathrm{~nm}$ in size, leading to the highest specific surface area of this set of samples $\left(29.9 \pm 0.1 \mathrm{~m}^{2} \cdot \mathrm{g}^{-1}\right)$. As a result, the samples prepared at $\mathrm{pH}=1,2$ and 8 , will be referred to as single crystals, microspheres and nano-powders, respectively. Regarding to impurities, the powder obtained at $\mathrm{pH}=1$ only presented negligible traces of carbon (typically less than $100 \mathrm{ppm}$ ) and water, whereas carbon content was close to $0.1 \mathrm{wt} \%$ for the other two powders. At the same time, the hydration rate increased up to around 0.4 $\mathrm{H}_{2} \mathrm{O}$ per mole of uranium for powders synthesized at $\mathrm{pH}=8$. Moreover, single crystals showed a very short deviation from the stoichiometry with the $\mathrm{O} / \mathrm{U}$ ratio estimated to less than 2.05 whereas the other two morphologies showed an $\mathrm{O} / \mathrm{U}$ ratio higher than 2.20.
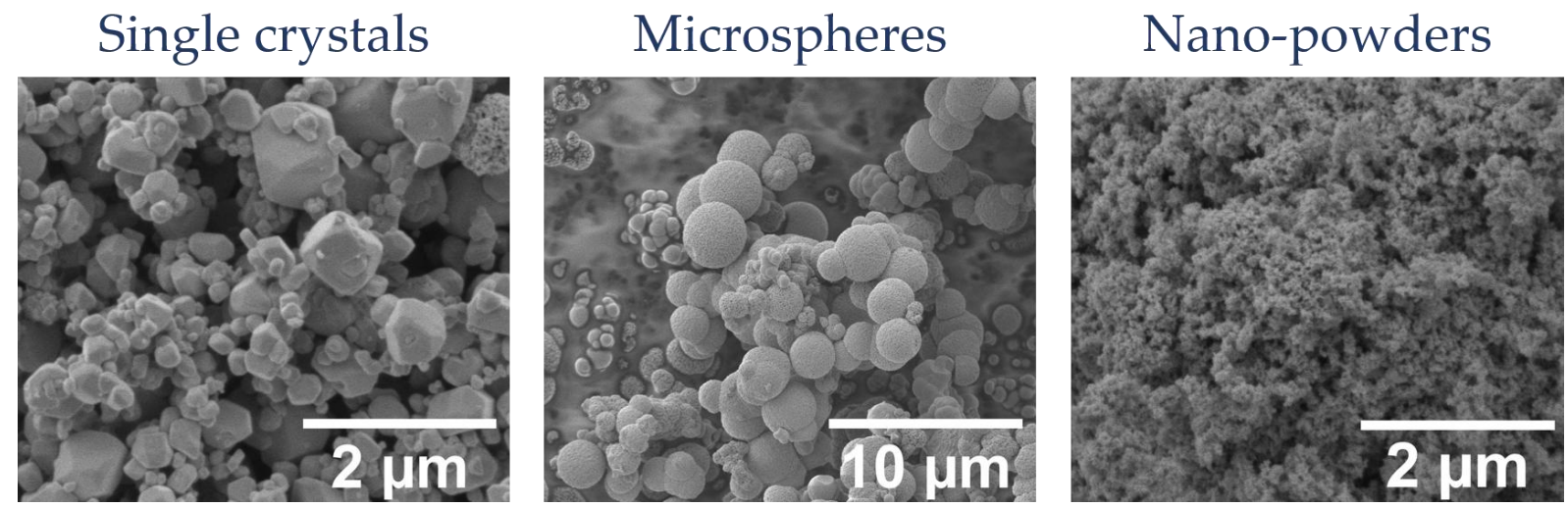

Figure 3. SEM images of three samples selected for the sintering study prepared at various $\mathrm{pH}$ values : $\mathrm{pH}=1-$ single crystals ; $\mathrm{pH}=2-$ microspheres ; $\mathrm{pH}=8-$ nano-powders.

Finally, the dilatometric study described above revealed that heating at $1600^{\circ} \mathrm{C}$ without applying a dwell was not enough to fully densify the samples for samples prepared at $\mathrm{pH}=1$ (single crystals) and 2 (microspheres), and that higher temperature and/or longer heating times were required. Conversely, heating the pellets prepared from powder synthesized at $\mathrm{pH}=8$ (nano-powders) at $1600^{\circ} \mathrm{C}$ appeared to be sufficient or even too high to 
complete the densification. Based on these differences, the study of the sintering of these three compounds was undertaken at three temperatures $\left(1500^{\circ} \mathrm{C}, 1600^{\circ} \mathrm{C}\right.$ and $\left.1700^{\circ} \mathrm{C}\right)$ considering four heat durations ( $1 \mathrm{~h}, 2 \mathrm{~h}, 4 \mathrm{~h}$ and $8 \mathrm{~h})$.

\subsubsection{Density measurements}

The geometrical density of each pellet was measured after applying various sintering heat treatments. In addition, density measurements by helium pycnometry were also carried out to discriminate open and closed porosities (Table 3). The geometrical densities mostly confirmed the conclusions made from dilatometric study. Indeed, density values between 90 and $95 \% \mathrm{TD}$ were obtained after 1 to 4 hours of heating at $1600^{\circ} \mathrm{C}$ for all the samples studied, whatever the initial morphology of the powder. Moreover, these values revealed that sintering at $1500^{\circ} \mathrm{C}$ with a holding time of at least 4 hours appeared sufficient to obtain satisfactory densities, and even higher than the values obtained at $1600^{\circ} \mathrm{C}$ for nano-powders (i.e. $94 \% \mathrm{TD}$ for $1500^{\circ} \mathrm{C}-1 \mathrm{~h}$ ). In the case of single crystals and microspheres, the same conditions (i.e. $1500^{\circ} \mathrm{C}-4 \mathrm{~h}$ ) allowed the significant reduction of the open porosity within the pellet (i.e. from more than $10 \%$ to $3 \%$ ). For all the morphologies, the final stage of sintering, which corresponds to the elimination of closed porosities and is generally characterized by relative densities higher than $92 \% \mathrm{TD}$, seemed to be reached under these conditions.

Finally, it is important to note that under certain sintering conditions, a loss of mechanical strength led to the full crumbling of the pellets. This phenomenon was observed for all morphologies after 8 hours of treatment at $1600^{\circ} \mathrm{C}$ and for several tests carried out at $1700^{\circ} \mathrm{C}$ (Table 3). High temperatures combined with excessive holding times then led to enhance stresses within the pellets [30], [31]. A comparable observation was made by Chambon et al. [15], who assigned this phenomenon to the presence of impurities in the starting powders, such as water and residual carbon, which react to form gaseous species (e.g. $\mathrm{CO})$. These gases are further trapped in the closed porosity during the sintering, which in return increase the pressure in the pores resulting in cracks or fractured pellets. 
Table 3. Geometrical and pycnometric relative densities and associated values of porosities of the sintered samples prepared. Uncertainty on density values: \pm $1 \%$.

\begin{tabular}{|c|c|c|c|c|c|c|}
\hline Morphology & $\begin{array}{c}\text { Temperature } \\
\left({ }^{\circ} \mathrm{C}\right)\end{array}$ & $\begin{array}{l}\text { Heating } \\
\text { time }(\mathrm{h})\end{array}$ & $\mathrm{d}_{\mathrm{geo}}(\%)$ & $\mathrm{d}_{\text {pycno }}(\%)$ & $\begin{array}{c}\text { Closed } \\
\text { porosity } \\
(\%)\end{array}$ & $\begin{array}{c}\text { Open } \\
\text { porosity } \\
(\%)\end{array}$ \\
\hline \multirow{11}{*}{$\begin{array}{c}\text { Single } \\
\text { Crystals }\end{array}$} & \multirow{4}{*}{1500} & 1 & 87 & 95 & 5 & 8 \\
\hline & & 2 & 87 & 98 & 2 & 11 \\
\hline & & 4 & 92 & 95 & 5 & 3 \\
\hline & & 8 & 94 & 97 & 3 & 3 \\
\hline & \multirow{4}{*}{1600} & 1 & 95 & 99 & 1 & 4 \\
\hline & & 2 & 95 & I & I & I \\
\hline & & 4 & 94 & 98 & 2 & 4 \\
\hline & & 8 & break & I & I & I \\
\hline & \multirow{3}{*}{1700} & 1 & 98 & 98 & 2 & 0 \\
\hline & & 2 & break & I & / & / \\
\hline & & 4 & break & I & I & I \\
\hline \multirow{11}{*}{ Microspheres } & \multirow{4}{*}{1500} & 1 & 86 & 97 & 3 & 11 \\
\hline & & 2 & 85 & 97 & 3 & 12 \\
\hline & & 4 & 91 & 94 & 6 & 3 \\
\hline & & 8 & 92 & 95 & 5 & 3 \\
\hline & \multirow{4}{*}{1600} & 1 & 90 & 95 & 5 & 5 \\
\hline & & 2 & 94 & I & I & I \\
\hline & & 4 & 91 & 96 & 4 & 5 \\
\hline & & 8 & break & I & I & I \\
\hline & \multirow{3}{*}{1700} & 1 & 96 & 97 & 3 & 1 \\
\hline & & 2 & break & 1 & I & I \\
\hline & & 4 & 96 & 97 & 3 & 1 \\
\hline \multirow{9}{*}{$\begin{array}{c}\text { Nano- } \\
\text { powders }\end{array}$} & \multirow{4}{*}{1500} & 1 & 94 & 98 & 2 & 4 \\
\hline & & 2 & 96 & I & 1 & 1 \\
\hline & & 4 & 96 & 99 & 1 & 3 \\
\hline & & 8 & 98 & I & I & I \\
\hline & \multirow{4}{*}{1600} & 1 & 93 & 98 & 2 & 5 \\
\hline & & 2 & 93 & 1 & 1 & 1 \\
\hline & & 4 & 92 & 98 & 2 & 6 \\
\hline & & 8 & break & 1 & 1 & 1 \\
\hline & 1700 & $1-4$ & break & 1 & 1 & 1 \\
\hline
\end{tabular}




\subsubsection{Grains size}

In the absence of exaggerated growth phenomena, the grain size distribution in a sintered ceramic material is generally described through a log-normal model [32]-[34]. This was also the case whatever the sample considered in this study, as the logarithm of the frequency of grain size systematically followed a Gaussian distribution (examples for the three powders sintered at $1600^{\circ} \mathrm{C}$ for $1 \mathrm{~h}$ are represented in Figure 4). Therefore, all the results are expressed as the median diameter grain size with the associated standard deviation.
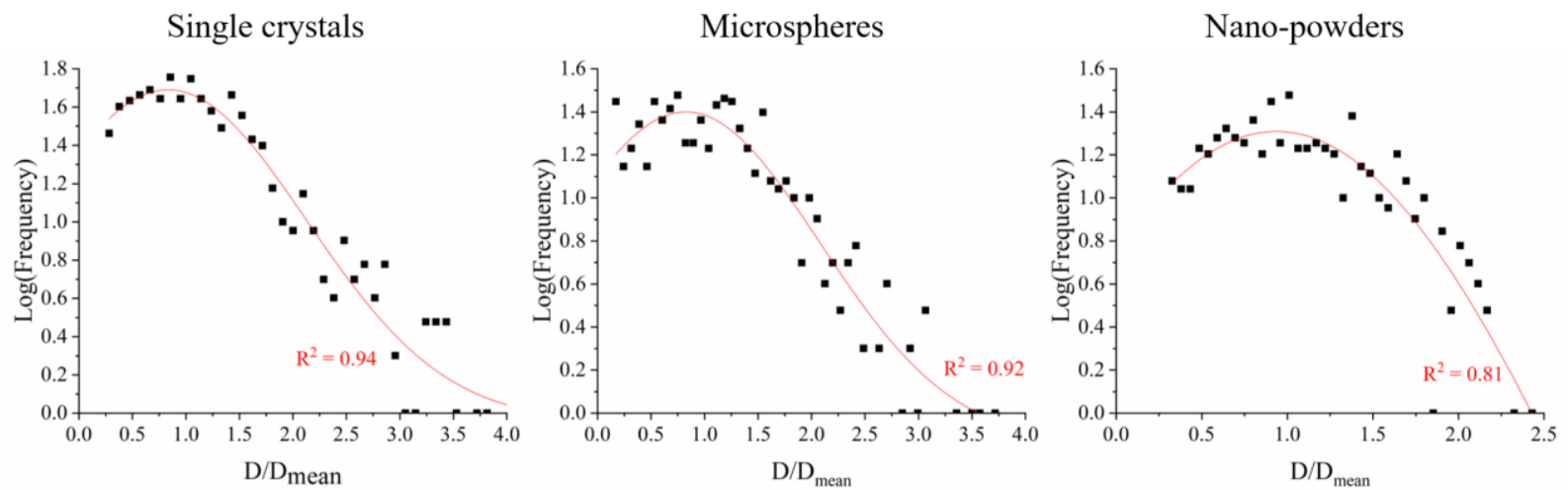

Figure 4. Representation of the logarithm of the frequency as a function of the median grain size for the three morphologies after sintering at $1600^{\circ} \mathrm{C}$ for 1 hour. The red curve represents the Gaussian fit.

Typical evolution of the microstructure of the pellets as a function of the sintering temperature (for a one hour plateau) is illustrated in Figure 5 for the three morphologies investigated. For single crystals and microspheres, the increase of the grain size as well as the decrease of the open porosity were clearly observed when rising the sintering temperature. Indeed, for both morphologies, the median grain size increased from less than $1 \mu \mathrm{m}$ after sintering at $1500^{\circ} \mathrm{C}$ up to $5 \mu \mathrm{m}$ at $1700^{\circ} \mathrm{C}$ with a grain size distribution ranging from 1 to 9 $\mu \mathrm{m}$. In contrast, the median grain size did not change significantly as a function of the sintering temperature for nano-powders (i.e. 3-4 $\mu \mathrm{m}$ ). In this case, although starting from nanometric powders, micrometric grain sizes were finally obtained in pellets. This behaviour can be explained by the higher reactivity of the nano-powders which led to faster the grain growth kinetics. In addition, it is worth noting the low inter-granular porosity of the pellets prepared from nano-powders at $1500^{\circ} \mathrm{C}$ and $1600^{\circ} \mathrm{C}$ compared to the two other morphologies. 

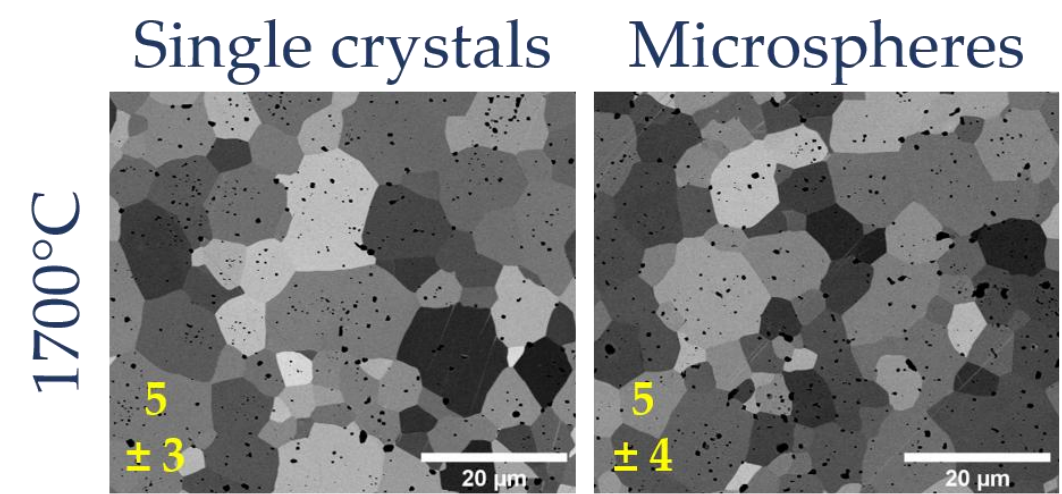

Nano-powders
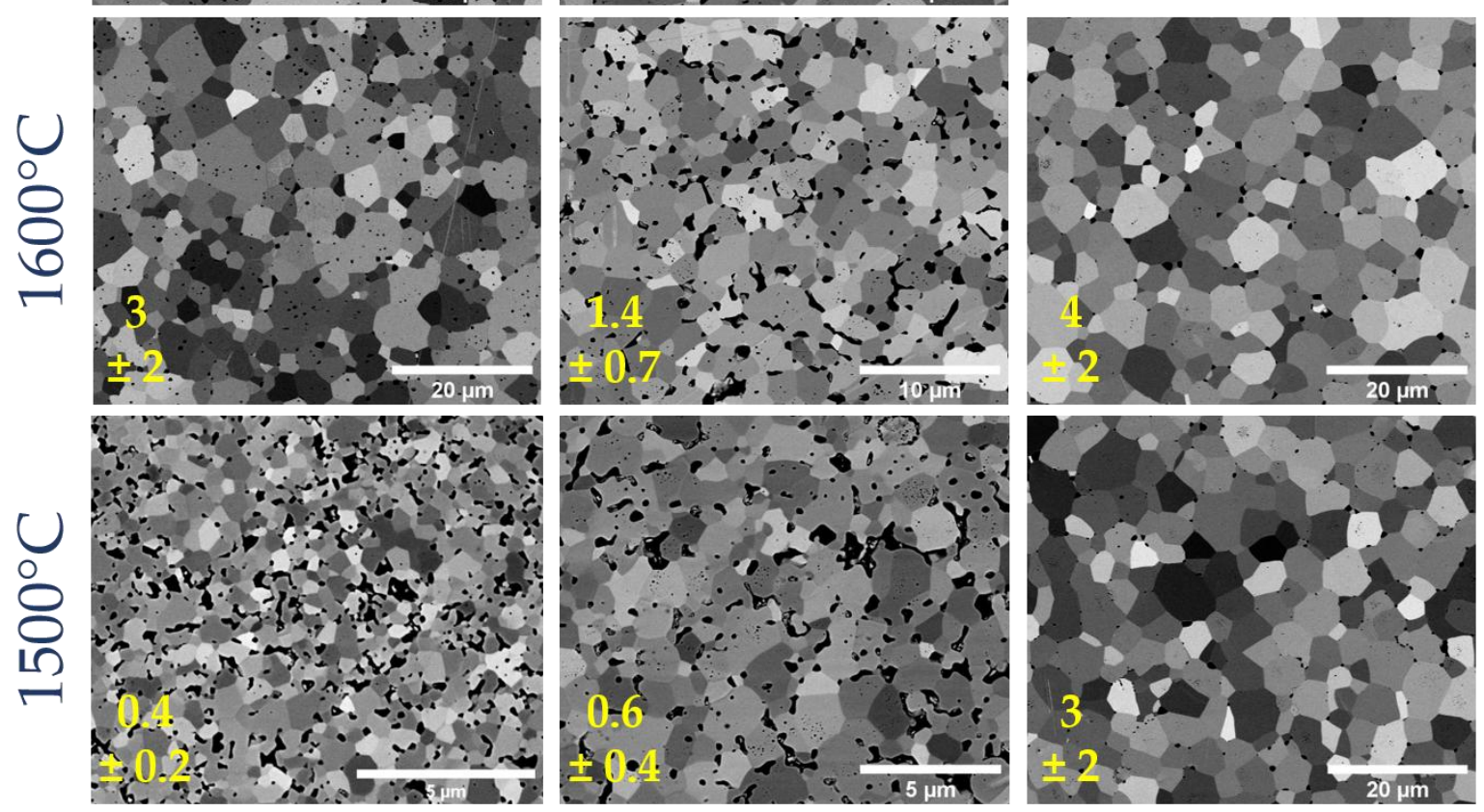

Figure 5. Variation of the grain size as a function of the morphology of the initial powders and the sintering temperature for a holding time of 1 hour. The median grain size is indicated in yellow in the pictures and expressed in $\mu \mathrm{m}$.

\subsubsection{Sintering map}

The sintering map is a graphical representation of the variation of the mean (or median in this paper) grain size as a function of the relative density of a sample [35], [36]. This tool is very interesting to highlight the impact of powder preparation conditions (e.g. temperature, synthesis time and $\mathrm{pH}$ ) on sintering, and to monitor the microstructure of the final sample. Nevertheless, only few data were reported for actinide-based compounds, including oxides. For example, Clavier et al. built the sintering map for $\mathrm{ThO}_{2}$ by combining in situ grain size determination by High-Temperature Environmental Scanning Electron Microscopy (HT- 
ESEM) and density values extrapolated from dilatometric measurements [37]. More recently, sintering maps based on experimental data have been also reported for other An-based oxides such as $\mathrm{Th}_{1-\mathrm{x}} \mathrm{Y}_{\mathrm{x}} \mathrm{O}_{2-\mathrm{x} / 2}[38]$ and $(\mathrm{U}, \mathrm{Pu}) \mathrm{O}_{2 \pm \mathrm{x}}[39]$, [40].

Thus, the density and grain size values of the samples prepared in this work and reported in the previous sections were used to establish the three trajectories showing the impact of the powder morphology on the final microstructure of the $\mathrm{UO}_{2+x}$ pellets (Figure 6).

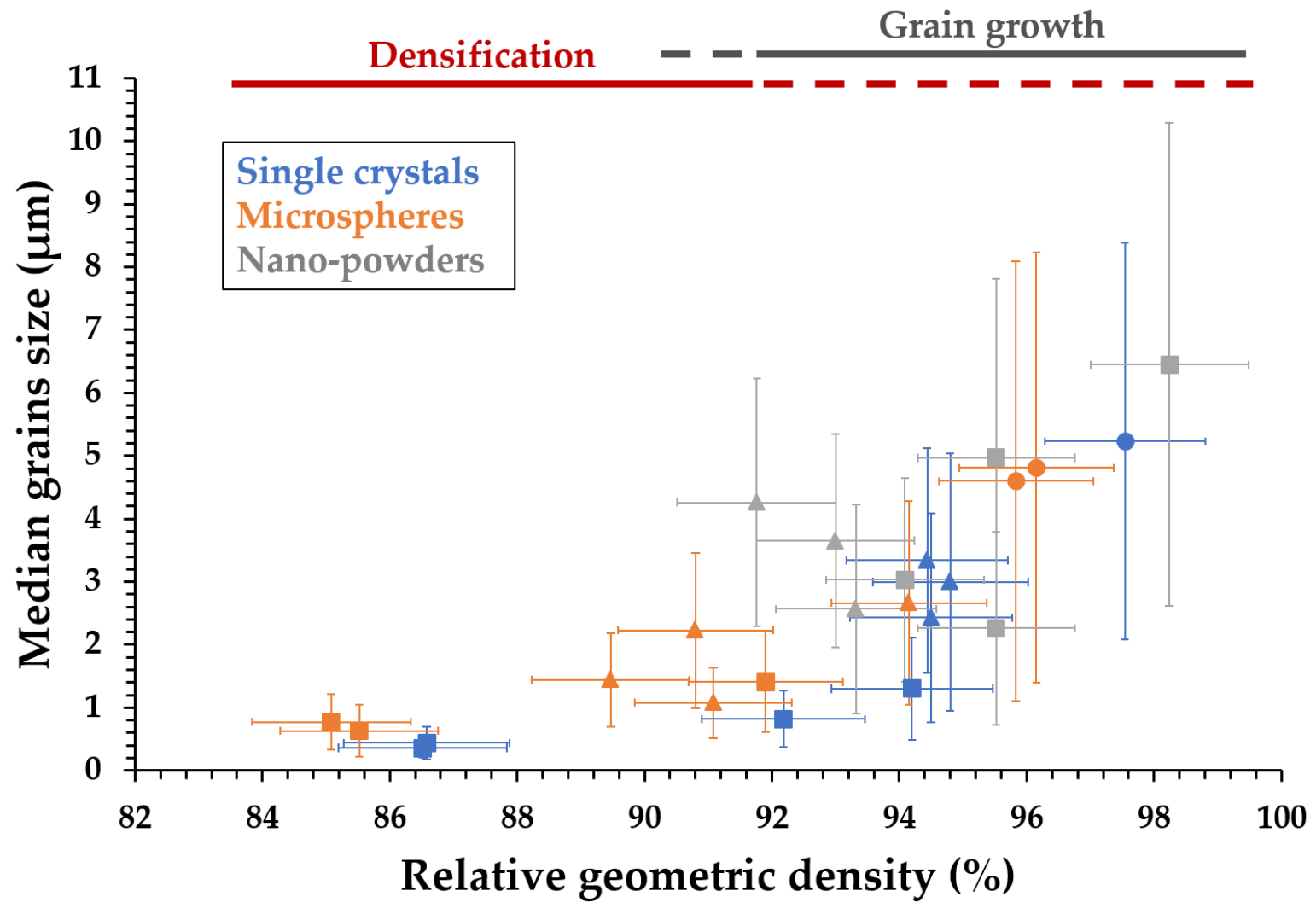

Figure 6. Sintering map of uranium oxides prepared by hydrothermal conversion of oxalate precursors. Single crystals are represented in blue, microspheres in orange and nano-powders in grey. Symbols account for the three sintering temperatures investigated, $1500^{\circ} \mathrm{C}(\boldsymbol{\nabla}) ; 1600^{\circ} \mathrm{C}(\boldsymbol{\Delta})$ and $1700^{\circ} \mathrm{C}(\bullet)$.

The behaviour of single crystals and microspheres was in good agreement with the sintering trajectories generally observed in the literature [37]-[39], [41]-[43]. Indeed, the development of the microstructure was divided in two parts: the first one was mainly governed by the densification of the sample (from 85 to $92 \%$ TD) and was accompanied by a limited grain growth. As such, it was considered to account for the end of the intermediate step of the sintering process, which corresponds to the elimination of open porosity. 
Subsequently, the second part was characterised by the significant increase of the grain size (typically by a factor of 2 or 3 ) and is only accompanied by a slight densification $(<5 \%)$. The transition between these two regimes of microstructure development typically occurred for relative densities ranging between 91 and $95 \% \mathrm{TD}$, which is in agreement with the empirical limit of $92 \%$ TD reported by Bernache-Assolant et al. [25].

In contrast, the behaviour of nano-powders differed significantly from the other two morphologies. As described above, only data obtained after heating at $1500^{\circ} \mathrm{C}$ and $1600^{\circ} \mathrm{C}$ were compiled to plot the sintering trajectory, the samples sintered at $1700^{\circ} \mathrm{C}$ being broken. In this case, it should be noted that the relative densities were systematically higher than $90 \%$ which led to observe only a grain growth step on the sintering map. Thus, the densification mainly occurred at lower temperature compared to the other two morphologies.

To our knowledge, such a low temperature of densification for uranium and/or thorium oxides was only reported up to now by using spark plasma sintering which is known to improve the sintering kinetics [20], [44], [45]. On this basis, nano-powders synthesised through hydrothermal conversion of uranium(IV) oxalate at $\mathrm{pH}=8$ clearly exhibited the best ability to sintering among the set of samples investigated. Their large specific surface area, which increased their reactivity, allowed the significant reduction of the sintering temperature by at least $200^{\circ} \mathrm{C}$ (i.e. $\mathrm{T} \leq 1500^{\circ} \mathrm{C}$ ) compared to the current nuclear fuel fabrication processes [7], [46] to achieve densities close to $95 \%$ TD.

\subsection{Grain growth mechanisms}

\subsubsection{Kinetics}

The evolution of the average grain size within a porous ceramic material can be described by the equation:

$$
D^{n}-D_{0}^{n}=k t
$$

Where $\mathrm{D}\left(\right.$ or $\mathrm{D}_{0}$ ) is the median grain diameter at time $\mathrm{t}$ (or $\mathrm{t}=0$ ) and $\mathrm{n}$ is a whole number depending on the diffusion mechanism responsible for grain growth. $\mathrm{k}$ is the rate constant and depends on temperature according to the Arrhenius' law:

$k=k_{0} \times e^{\left(\frac{-E_{A}}{R T}\right)}$ 
With $R$ the universal constant of perfect gases, $\mathrm{E}_{\mathrm{A}}$ the activation energy (expressed in $\mathrm{J} / \mathrm{mol}$ ) and $\mathrm{T}$ the temperature.

In our case, the use of submicrometric starting powders means that $\mathrm{D}_{0}$ is much lower than D [47]. It is then possible to simplify the expression of grain growth as follows :

$$
D^{n}=k_{0} e^{\left(\frac{-E_{A}}{R T}\right)} t
$$

This equation was established considering that the granulometric distribution within the sample remained similar whatever the sintering time. Based on this hypothesis, the normalized distribution should be invariant as a function of time [48]. This co-called selfsimilarity of the grain size distribution as a function of time was reported experimentally [38], [39], [49], [50] and by Monte Carlo calculations [51] for ceramic systems and resulted from the invariance of each grain class (i.e. constant $\mathrm{D} / \mathrm{D}_{\text {mean }}$ ratio).

In this work, a systematic study of the cumulated grain size distribution was undertaken at different temperatures and systematically led to a sigmoidal trend whatever the starting powder considered. An example taken from the pellets prepared from nano-powders at $1500^{\circ} \mathrm{C}$ is presented in Figure 7 (see Figure S1 in Supporting Information for pellets obtained from single crystals and microspheres). In addition, the standardised particle size distribution $\left(\mathrm{D} / \mathrm{D}_{\text {mean }}\right)$ within the samples appeared almost identical whatever the sintering time: the grain growth process was therefore considered as normal. This means that no exaggerated growth, leading to the detachment of intergranular pores and grain boundaries, took place during the sintering process. 


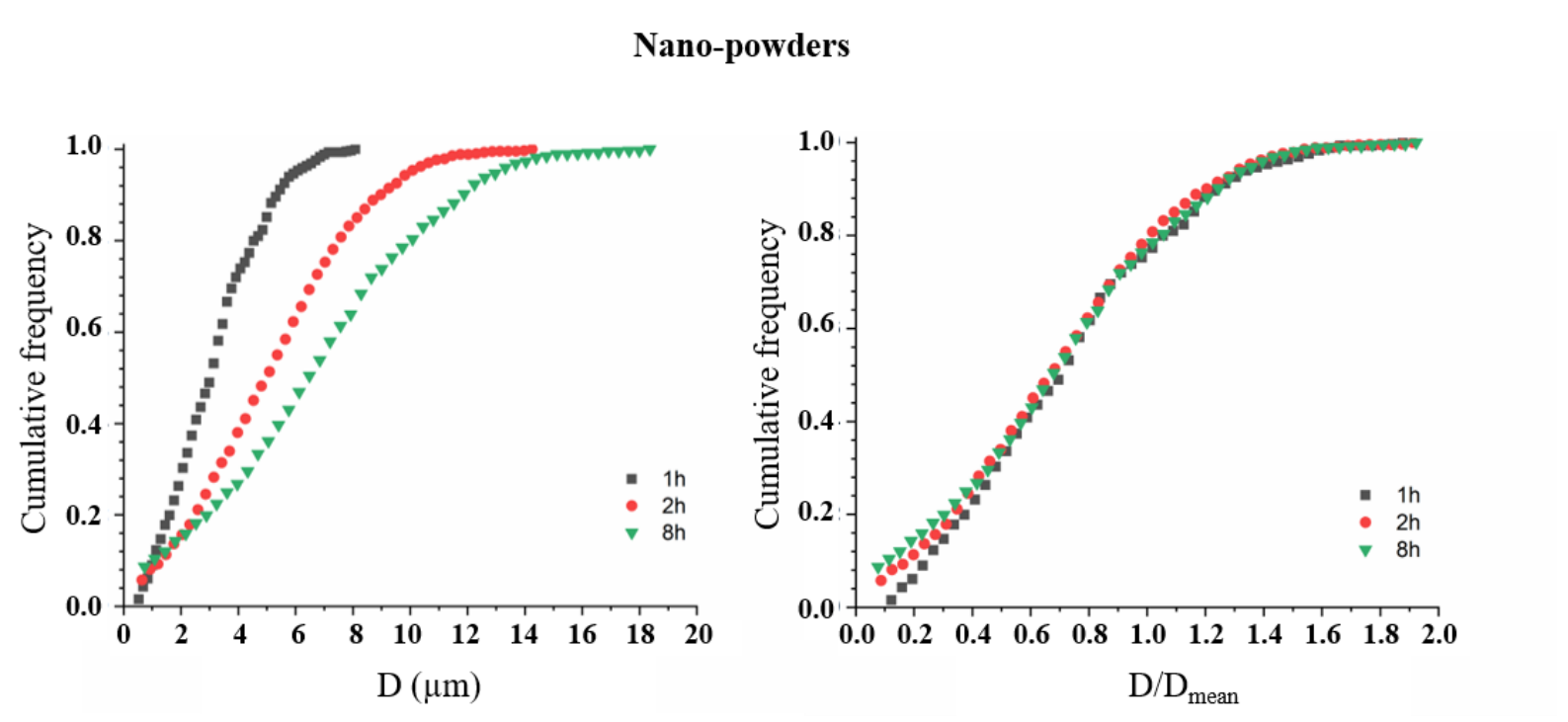

Figure 7. Representation of the particle size distribution (represented as the cumulative frequency) within the pellets obtained from nano-powders at $1500^{\circ} \mathrm{C}$.

For all the samples studied, the grain size distribution being normal, the value of the exponent $\mathrm{n}$, characteristic of the grain growth mechanism, was extracted from the equation:

$n \ln (D)=\ln (t)-\frac{E_{A}}{R T}+\ln \left(k_{0}\right)$

For the three studied morphologies and the set of sintering conditions tested, the variation of $\ln (\mathrm{D})$ as a function of $\ln (\mathrm{t})$ is shown in Figure 8. The small number of experimental data points considered for each temperature, as well as the wide particle size distribution observed in the samples, did not allow to systematically conclude unambiguously to a linear variation. The value of $\mathrm{n}$ was therefore estimated at $1500^{\circ} \mathrm{C}$ for the three morphologies and at $1600^{\circ} \mathrm{C}$ for single crystals only.

Figure 8. Variation of $\ln (\mathrm{D})$ as a function of $\ln (\mathrm{t})$ during sintering at $1500^{\circ} \mathrm{C}$ : $\quad$; $1600^{\circ} \mathrm{C}: \triangle ; 1700^{\circ} \mathrm{C}: \circ$. 

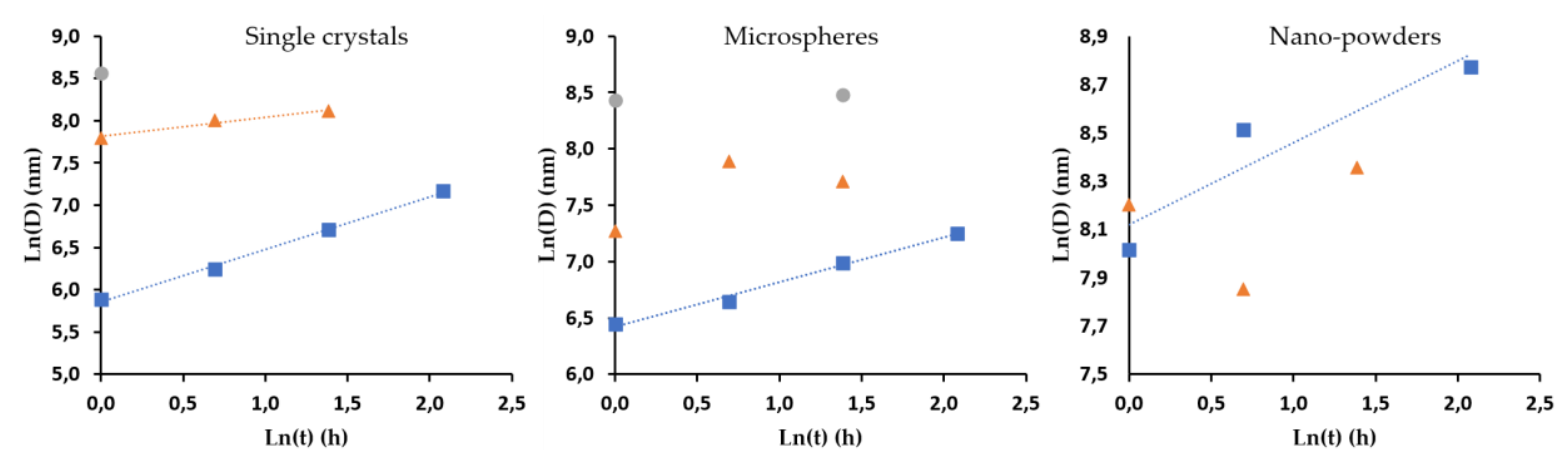

For single crystals and microspheres, the $n$ value was close to $1.5 \pm 0.5$ and $2.5 \pm 0.5$ at $1500^{\circ} \mathrm{C}$ whereas it reached $3 \pm 1$ for nano-powders. Based on the high uncertainty for the determination of this $\mathrm{n}$ value for nano-powders, we can estimate that the three morphologies have a similar value close to 2 . This result is in good agreement with the early works of McEwan et al. who studied grain growth kinetics in $\mathrm{UO}_{2}$ in a wide temperature range starting at $1550^{\circ} \mathrm{C}$ [33], [52]. In the case of a material containing impurities, this corresponds to a granular growth controlled by the movement of the grain boundaries but slowed down by the presence of impurities within the grain boundaries (so-called "solute drag" phenomenon). This result is consistent with the observation of residual carbon trapped between the crystallites. Indeed, in our previous work on $\mathrm{ThO}_{2}$ samples prepared by the same hydrothermal process than that described in this paper [18], EXAFS experiments allowed to exclude the presence of residual carbon trapped inside the unit cell and rather accounted for the existence of amorphous carbon between the crystallites. Such impurities would finally slow down the motion of grain boundaries during the sintering process by limiting the diffusion of uranium. In case of single crystals, which were found to be almost carbon-free (cf. Table 2), the presence of numerous intragranular pores, as shown in Figure 5, could lead to the same phenomena, i.e. decrease of the grain boundaries motion [25].

In the case of the sintering of single crystals, however, the $n$ value estimated at $1600^{\circ} \mathrm{C}$ was close to 4 . This indicated that the movement of the grain boundaries was then controlled by diffusion at the grain boundaries, and that the braking phenomenon described above has disappeared at this temperature. The increase of the sintering temperature could therefore have allowed a fraction of the residual carbon to be removed. Moreover, this result appeared in agreement with the observations made by Nkou Bouala et al. on the sintering of $\mathrm{ThO}_{2}$ between 1000 and $1300^{\circ} \mathrm{C}$ for which diffusion took place preferentially at the grain boundaries [53].

\subsubsection{Activation energy}


Subsequently, the activation energy related to grain growth of $\mathrm{UO}_{2+\mathrm{x}}$ samples was determined from equation (5) for the three morphologies studied. For pellets prepared from single crystals and microspheres, using the results obtained at 1500,1600 and $1700^{\circ} \mathrm{C}$ for various holding times led to a consistent set of data, thus allowing to propose an $\mathrm{E}_{\mathrm{A}}$ value with an associated uncertainty. For nano-powders, only two heating temperatures allowed the preparation of sintered pellets, which precludes any accurate determination of the activation energy. Nevertheless, an indicative order of magnitude is still supplied for comparison purposes.

Although numerous studies were dedicated to the determination of activation energies related to grain growth in $\mathrm{UO}_{2}$ samples since the sixties, the range of values reported in the literature remains very scattered. This first arises from the wide domain of temperatures investigated by the authors, typically going from 1400 to $2500^{\circ} \mathrm{C}$, but also from the mechanism attached to grain growth. Indeed, as pointed out by Bourgeois et al. [54], the choice of the $\mathrm{n}$ exponent is crucial for determining the activation energy value, even if different interpretations can be linked to the same $n$ value. A common trend can still be described when selecting the data determined in temperature ranges as close as possible to the one used in this work (Table 4), with $\mathrm{E}_{\mathrm{A}}$ mostly values close to $450 \mathrm{~kJ}^{\mathrm{mol}}{ }^{-1}$.

Table 4. Activation energies associated with grain growth during the sintering of the three $\mathrm{UO}_{2+\mathrm{x}}$ morphologies studied, and comparison with literature.

\begin{tabular}{cccc}
\hline Authors & $\begin{array}{c}\text { Temperature } \\
\text { range }\left({ }^{\circ} \mathbf{C}\right)\end{array}$ & $\mathbf{E}_{\mathbf{A}}\left(\mathbf{k J . m o l} \mathbf{~}^{\mathbf{1}}\right)$ & Reference \\
\hline Mc Ewan & $1550-2440$ & 364 & {$[33],[52]$} \\
Mc Ewan et al. & $1550-2440$ & 456 & {$[33]$} \\
Soliman et al. & $1600-1900$ & 450 & {$[54]$} \\
Glodeanu et al. & $1600-1800$ & 467 & {$[55]$} \\
\hline Powder morphology & Temperature & $\mathbf{E}_{\mathbf{A}}\left(\mathbf{k J . m o l} \mathbf{~}^{\mathbf{1}}\right)$ & Reference \\
\hline range $\left({ }^{\circ} \mathbf{C}\right)$ & $422 \pm 50$ & This work \\
Mingle crystals & $1500-1700$ & $283 \pm 63$ & \\
Microspheres & $1500-1700$ & $\approx 100-150$ & \\
\hline
\end{tabular}


In good agreement with these data, the value determined during this study for the

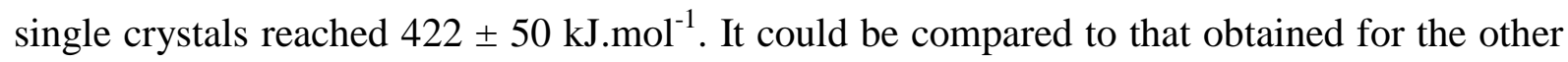
samples, as they all present the same value of $\mathrm{n}$, i.e. share a common mechanism driving grain growth. On this basis, the value determined when using single crystals appears to be significantly higher than the activation energy obtained when using microspheres, and than the one estimated for nano-powders. Even if the different powders used in this work initially present different physico-chemical characteristics (Table 2), one should expect that these differences vanished when heated at high temperature under a similar atmosphere. As a matter of example, the $\mathrm{O} / \mathrm{M}$ ratio should be equal in all the pellets prepared at a given temperature, assuming that a thermodynamic equilibrium was reached for all the samples. On this basis, the variation observed in the $\mathrm{E}_{\mathrm{A}}$ values depending on the powder initially used could possibly be ascribed to the initial crystallite size in the grains, associated to their mosaicity (i.e. angle of misorientation between the crystallites). Indeed, it was recently shown that this parameter clearly impacts the kinetics of sintering by establishing diffusion short-cuts in the sample [56]. Hence, the large crystallites evidenced in the so-called single-crystals are probably strongly correlated, while the nano-sized domains forming the other two samples are more disoriented. Part of this disorder could be retained within the grains at high temperatures, and explain the variation in the activation energy.

Furthermore, one can note that the activation energy estimated for grain growth in pellets made from nano-powders is much lower than the values usually reported in the literature for $\mathrm{UO}_{2+\mathrm{x}}$ (i.e. around 100-150 kJ.mol${ }^{-1}$ ). This variation related to the morphology was consistent with the literature describing the phenomena of grain growth in nanometric materials [57], [58]. Indeed, Shukla et al. showed that the activation energy of grain growth of a nanoscale yttrium-doped zirconia powder was much lower than that of the bulk material (i.e. $13 \mathrm{~kJ} \cdot \mathrm{mol}^{-1}$ compared to $580 \mathrm{~kJ} \cdot \mathrm{mol}^{-1}$ ) [57].

\section{Conclusion}

The sintering of uranium oxide powders prepared by hydrothermal conversion of the oxalate precursor has been studied. Initially, a dilatometric study revealed significant differences in the material behaviour during densification depending on the conditions used for the powders preparation. Nevertheless, only the $\mathrm{pH}$ of the starting solution appeared to largely modify the sintering of the pellets, notably through the morphology of the powders. 
Among the morphologies obtained, three samples with varied morphologies (single crystals $-\mathrm{pH}=1$, microspheres $-\mathrm{pH}=2$ and nano- powders $-\mathrm{pH}=8$ ) were selected to study their sintering behaviour more precisely. Densitometric and granulometric data allowed establishing the sintering map for each of the powders considered. All the powders exhibited relative densities above $90 \% \mathrm{TD}$ after a 4 -hour heat treatment at $1500^{\circ} \mathrm{C}$. In the case of single crystals and microspheres, densities greater than or equal to $96 \%$ were also obtained at $1700^{\circ} \mathrm{C}$. In contrast, a sintering time of only 2 to 8 hours at $1500^{\circ} \mathrm{C}$ led to comparable results for nano-powders prepared at $\mathrm{pH}=8$, due to their higher reactivity. The study of the grains size confirmed the difference between the behaviour of single crystals and microspheres, on the one hand, and nano-powders, on the other hand. For the first two powders, the grains size increased with temperature and sintering time, whereas this growth remains very limited in the case of nano-powders.

The study of grain growth mechanisms finally revealed a behaviour consistent with the presence of insoluble impurities (carbon) or porosity in the uranium oxide pellet. The determination of the associated activation energy also showed a strong variability depending on the sample used, from $422 \pm 50 \mathrm{~kJ} \mathrm{~mol}^{-1}$ for single crystals down to about $100-150 \mathrm{~kJ} . \mathrm{mol}^{-1}$ for nano-powders, which could result from the powder microstructure. Overall, the results obtained from the nano-powders prepared at $\mathrm{pH}=8$ under hydrothermal conditions seem to be the most promising, with a sintering temperature $200^{\circ} \mathrm{C}$ lower than that found for the other morphologies or that usually used to manufacture nuclear fuel (i.e. $1700^{\circ} \mathrm{C}$ ).

These observations therefore confirm that the hydrothermal conversion of oxalates can be considered as a promising route for the synthesis of actinide oxides, which can subsequently be sintered without any preliminary treatment. In terms of process, this allows to simplify the conversion of oxalates to oxides by comparison to the conventional process.

\section{Conflicts of interest}

There are no conflicts to declare.

\section{Acknowledgements}

Authors are grateful to M. Zunino for his help during sintering experiments. Authors also would like to thank the Materials Federative Project included in the NEEDS program (Nucléaire, Energie, Environnement, Déchets, Société) of CNRS for its continuous financial 
support. This study received funding from the GENIORS project (H2020 Euratom Research and Innovation

Programme under grant agreement no. 755171). 


\section{References}

[1] D. C. Crawford, D. L. Porter, and S. L. Hayes, "Fuels for sodium-cooled fast reactors: US perspective," J. Nucl. Mater., vol. 371, no. 1-3, pp. 202-231, 2007.

[2] S. Vaudez, J. Léchelle, S. Berzati, and J.-M. Heintz, "Assessing the oxygen stoichiometry during the sintering of $(\mathrm{U}, \mathrm{Pu}) \mathrm{O}_{2}$ fuel," J. Nucl. Mater., vol. 460, pp. 221225, May 2015, doi: 10.1016/j.jnucmat.2015.02.005.

[3] R. Vauchy et al., "Actinide Oxidation State and O/M Ratio in Hypostoichiometric Uranium-Plutonium-Americium $\mathrm{U}_{0.750} \mathrm{Pu}_{0.246} \mathrm{Am}_{0.004} \mathrm{O}_{2-\mathrm{x}}$ Mixed Oxides," Inorg. Chem., vol. 55, no. 5, pp. 2123-2132, Mar. 2016, doi: 10.1021/acs.inorgchem.5b02533.

[4] J. G. O. Marques, A. L. Costa, and C. Pereira, "Na-O-H thermochemical water splitting cycle: A new approach in hydrogen production based on sodium cooled fast reactor," Int. J. Hydrog. Energy, vol. 43, no. 16, pp. 7738-7753.

[5] J. Serp, C. Poinssot, and S. Bourg, "Assessment of the Anticipated Environmental Footprint of Future Nuclear Energy Systems. Evidence of the Beneficial Effect of Extensive Recycling," Energies, vol. 10, no. 9, Art. no. 9, Sep. 2017, doi: 10.3390/en10091445.

[6] D. Vollath, H. Wedemeyer, H. Elbel, and E. Günther, "On the Dissolution of (U,Pu) $\mathrm{O}_{2}$ Solid Solutions with Different Plutonium Contents in Boiling Nitric Acid," Nucl. Technol., vol. 71, no. 1, pp. 240-245, Oct. 1985, doi: 10.13182/NT85-A33723.

[7] T. Abe and K. Asakura, "Uranium Oxide and MOX Production," in Comprehensive Nuclear Materials, R. J. M. Konings, Ed. Oxford: Elsevier, 2012, pp. 393-422.

[8] S. Vaudez, R. C. Belin, L. Aufore, P. Sornay, and S. Grandjean, "A new fabrication route for SFR fuel using $(\mathrm{U}, \mathrm{Pu}) \mathrm{O}_{2}$ powder obtained by oxalic co-conversion," J. Nucl. Mater., vol. 442, no. 1, pp. 227-234, Nov. 2013, doi: 10.1016/j.jnucmat.2013.08.023.

[9] F. Abraham, B. Arab-Chapelet, M. Rivenet, C. Tamain, and S. Grandjean, "Actinide oxalates, solid state structures and applications," Coord. Chem. Rev., vol. 266-267, pp. 28-68, May 2014, doi: 10.1016/j.ccr.2013.08.036.

[10] N. Vigier, S. Grandjean, B. Arab-Chapelet, and F. Abraham, "Reaction mechanisms of the thermal conversion of $\mathrm{Pu}(\mathrm{IV})$ oxalate into plutonium oxide," J. Alloys Compd., vol. 444-445, pp. 594-597, Oct. 2007, doi: 10.1016/j.jallcom.2007.01.057.

[11] L. Desfougeres, E. Welcomme, M. Ollivier, P.M. Martin, J. Hennuyer, M.O.J.Y. Hunault, R. Podor, N. Clavier, L. Favergeon, "Oxidation as an Early Stage in the Multistep Thermal Decomposition of Uranium(IV) Oxalate into $\mathrm{U}_{3} \mathrm{O}_{8}$," Inorg. Chem., vol. 59, no. 12, pp. 8589-8602, Jun. 2020, doi: 10.1021/acs.inorgchem.0c01047.

[12] J. Martinez, N. Clavier, T. Ducasse, A. Mesbah, F. Audubert, B. Corso, N. Vigier, N. Dacheux, "From uranium(IV) oxalate to sintered $\mathrm{UO}_{2}$ : Consequences of the powders' thermal history on the microstructure," J. Eur. Ceram. Soc., vol. 35, no. 16, pp. 45354546, Dec. 2015, doi: 10.1016/j.jeurceramsoc.2015.07.010.

[13] G. D. White, L. A. Bray, and P. E. Hart, "Optimization of thorium oxalate precipitation conditions relative to derived oxide sinterability," J. Nucl. Mater., vol. 96, no. 3, pp. 305-313, Feb. 1981, doi: 10.1016/0022-3115(81)90574-2.

[14] K. Asakura and K. Takeuchi, "Effect of residual carbon on the sintering behavior of MOX pellets," J. Nucl. Mater., vol. 348, no. 1, pp. 165-173, Jan. 2006, doi: 10.1016/j.jnucmat.2005.09.016. 
[15] C. Chambon, S. Vaudez, and J.-M. Heintz, "De-densification mechanisms of yttriadoped cerium oxide during sintering in a reducing atmosphere," J. Am. Ceram. Soc., vol. 101, no. 11, pp. 4956-4967, 2018, doi: 10.1111/jace.15741.

[16] O. Walter, K. Popa, and O. D. Blanco, "Hydrothermal decomposition of actinide(IV) oxalates: a new aqueous route towards reactive actinide oxide nanocrystals," Open Chem., vol. 14, no. 1, pp. 170-174, 2016, doi: 10.1515/chem-2016-0018.

[17] K. Popa, O. Walter, O. Dieste Blanco, A. Guiot, D. Bouëxière, J.Y. Colle, L. Martel, M. Naji, D. Manara, "A low-temperature synthesis method for $\mathrm{AnO}_{2}$ nanocrystals $(\mathrm{An}=\mathrm{Th}$, $\mathrm{U}, \mathrm{Np}$, and $\mathrm{Pu}$ ) and associate solid solutions," CrystEngComm, vol. 20, no. 32, pp. 4614-4622, 2018, doi: 10.1039/C8CE00446C.

[18] J. Manaud, J. Maynadié, A. Mesbah, M.O.J.Y. Hunault, P.M. Martin, M. Zunino, N. Dacheux, N. Clavier, "Hydrothermal Conversion of Thorium Oxalate into $\mathrm{ThO}_{2} \cdot \mathrm{nH}_{2} \mathrm{O}$ Oxide," Inorg. Chem., vol. 59, no. 20, pp. 14954-14966, Oct. 2020, doi: 10.1021/acs.inorgchem.0c01633.

[19] J. Manaud, J. Maynadié, A. Mesbah, M.O.J.Y. Hunault, P.M. Martin, M. Zunino, D. Meyer, N. Dacheux, N. Clavier, "Hydrothermal Conversion of Uranium(IV) Oxalate into Oxides: A Comprehensive Study," Inorg. Chem., vol. 59, no. 5, pp. 3260-3273, Mar. 2020, doi: 10.1021/acs.inorgchem.9b03672.

[20] L. Balice, D. Bouëxière, M. Cologna, A. Cambriani, J.F. Vigier, E. De Bona, G.D. Sorarù, C. Kübel, O. Walter, K. Popa, "Nano and micro $\mathrm{U}_{1-\mathrm{x}} \mathrm{Th}_{\mathrm{x}} \mathrm{O}_{2}$ solid solutions: From powders to pellets," J. Nucl. Mater., vol. 498, pp. 307-313, Jan. 2018, doi: 10.1016/j.jnucmat.2017.10.042.

[21] E. De Bona, L. Balice, L. Cognini, M. Holzhäuser, K. Popa, O. Walter, M. Cologna, D. Prieur, T. Wiss, G. Baldinozzi, "Single-step, high pressure, and two-step spark plasma sintering of $\mathrm{UO}_{2}$ nanopowders," J. Eur. Ceram. Soc., Jan. 2021, doi: 10.1016/j.jeurceramsoc.2021.01.020.

[22] A. Rabenau, "The Role of Hydrothermal Synthesis in Preparative Chemistry," Angew. Chem. Int. Ed., vol. 24, no. 12, pp. 1026-1040, 1985, doi: 10.1002/anie.198510261.

[23] R. Podor, X. Le Goff, J. Lautru, H.-P. Brau, M. Massonnet, and N. Clavier, "SEraMic: a semi-automatic method for the segmentation of grain boundaries," J. Eur. Ceram. Soc., vol. 41, no. 10, pp. 5349-5358, Aug. 2021, doi: 10.1016/j.jeurceramsoc.2021.03.062.

[24] C. A. Schneider, W. S. Rasband, and K. W. Eliceiri, "NIH Image to ImageJ: 25 years of image analysis," Nat. Methods, vol. 9, no. 7, pp. 671-675, Jul. 2012, doi: 10.1038/nmeth.2089.

[25] D. Bernache-Assollant and J.-P. Bonnet, Frittage: aspects physico-chimiques. Ed. Techniques Ingénieur, 2005.

[26] M. O. Tucker, "The growth of grain edge porosity in irradiated $\mathrm{UO}_{2}$," J. Nucl. Mater., vol. 79, no. 1, pp. 206-213, Jan. 1979, doi: 10.1016/0022-3115(79)90448-3.

[27] C. S. Morgan, K. H. McCorkle, and G. L. Powell, "Pore Growth in Sintered Thoria," J. Am. Ceram. Soc., vol. 59, no. 3-4, pp. 104-107, 1976, doi: 10.1111/j.11512916.1976.tb09441.x.

[28] D. Prieur, F. Lebreton, P.M. Martin, A. Jankowiak, T. Delahaye, P. Dehaudt, P. Blanchart, "Reactive sintering of $\mathrm{U}_{1-\mathrm{y}} \mathrm{Am}_{\mathrm{y}} \mathrm{O}_{2 \pm \mathrm{x}}$ in overstoichiometric conditions," J. Eur. Ceram. Soc., vol. 32, no. 8, pp. 1585-1591, Jul. 2012, doi: 10.1016/j.jeurceramsoc.2011.12.017.

[29] V. Trillaud, J. Maynadié, J. Manaud, J. Hidalgo, D. Meyer, R. Podor, N. Dacheux, N. Clavier, "Synthesis of size-controlled $\mathrm{UO}_{2}$ microspheres from the hydrothermal 
conversion of U(IV) aspartate," CrystEngComm, vol. 20, no. 48, pp. 7749-7760, 2018, doi: 10.1039/C8CE01352G.

[30] D.-J. Chen and M. J. Mayo, "Rapid Rate Sintering of Nanocrystalline $\mathrm{ZrO}_{2}-3 \mathrm{~mol} \%$ $\mathrm{Y}_{2} \mathrm{O}_{3}$," J. Am. Ceram. Soc., vol. 79, no. 4, pp. 906-912, 1996, doi: 10.1111/j.11512916.1996.tb08524.x.

[31] W. Li and L. Gao, "Rapid sintering of nanocrystalline $\mathrm{ZrO}_{2}(3 \mathrm{Y})$ by spark plasma sintering," J. Eur. Ceram. Soc., vol. 20, no. 14, pp. 2441-2445, Dec. 2000, doi: 10.1016/S0955-2219(00)00152-7.

[32] P. Feltham, "Grain growth in metals," Acta Metall., vol. 5, no. 2, pp. 97-105, Feb. 1957, doi: 10.1016/0001-6160(57)90136-0.

[33] J. R. MacEwan, "Grain Growth in Sintered Uranium Dioxide: I, Equiaxed Grain Growth," J. Am. Ceram. Soc., vol. 45, no. 1, pp. 37-41, 1962, doi: https://doi.org/10.1111/j.1151-2916.1962.tb11026.x.

[34] H. Hallberg and Y. Zhu, "Stability of grain boundary texture during isothermal grain growth in $\mathrm{UO}_{2}$ considering anisotropic grain boundary properties," J. Nucl. Mater., vol. 465, pp. 664-673, Oct. 2015, doi: 10.1016/j.jnucmat.2015.06.052.

[35] S.-J. L. Kang and Y.-I. Jung, "Sintering kinetics at final stage sintering: model calculation and map construction," Acta Mater., vol. 52, no. 15, pp. 4573-4578, Sep. 2004, doi: 10.1016/j.actamat.2004.06.015.

[36] J. Kanters, U. Eisele, and J. Rödel, "Effect of initial grain size on sintering trajectories," Acta Mater., vol. 48, no. 6, pp. 1239-1246, Apr. 2000, doi: 10.1016/S13596454(99)00433-4.

[37] N. Clavier, R. Podor, L. Deliere, J. Ravaux, and N. Dacheux, "Combining in situ HTESEM observations and dilatometry: An original and fast way to the sintering map of $\mathrm{ThO}_{2}$," Mater. Chem. Phys., vol. 137, no. 3, pp. 742-749, Jan. 2013, doi: 10.1016/j.matchemphys.2012.10.003.

[38] Y. Cherkaski, N. Clavier, L. Brissonneau, R. Podor, and N. Dacheux, "Densification behavior and microstructure evolution of yttrium-doped $\mathrm{ThO}_{2}$ ceramics," J. Eur. Ceram. Soc., vol. 37, no. 10, pp. 3381-3391, Aug. 2017, doi: 10.1016/j.jeurceramsoc.2017.04.015.

[39] D. Qin, A. Mesbah, J. Lautru, S. Szenknect, N. Dacheux, and N. Clavier, "Reaction sintering of rhabdophane into monazite-cheralite $\mathrm{Nd}_{1-2 \mathrm{x}} \mathrm{Th}_{\mathrm{x}} \mathrm{Ca}_{\mathrm{x}} \mathrm{PO}_{4}(\mathrm{x}=0-0.1)$ ceramics," J. Eur. Ceram. Soc., vol. 40, no. 3, pp. 911-922, Mar. 2020, doi: 10.1016/j.jeurceramsoc.2019.10.050.

[40] J. Simeon, F. Lebreton, L. Ramond, F. La Lumia, N. Clavier, and G. Bernard-Granger, "Sintering of a $\mathrm{UO}_{2}-\mathrm{PuO}_{2}$ freeze-granulated powder under reducing conditions," J. Eur. Ceram. Soc., vol. 40, no. 15, pp. 5900-5908, Dec. 2020, doi: 10.1016/j.jeurceramsoc.2020.07.022.

[41] C. Clausell, A. Barba, L. Nuño, and J. C. Jarque, "Effect of average grain size and sintered relative density on the imaginary part $-\mu$ " of the complex magnetic permeability of $\left(\mathrm{Cu}_{0.12} \mathrm{Ni}_{0.23} \mathrm{Zn}_{0.65}\right) \mathrm{Fe}_{2} \mathrm{O}_{4}$ system," Ceram. Int., vol. 42, no. 3, pp. 42564261, Feb. 2016, doi: 10.1016/j.ceramint.2015.11.101.

[42] G. Bernard-Granger, C. Guizard, and A. Addad, "Sintering of an ultra pure $\alpha$-alumina powder: I. Densification, grain growth and sintering path," J. Mater. Sci., vol. 42, no. 15, pp. 6316-6324, Aug. 2007, doi: 10.1007/s10853-006-1206-1.

[43] L. Chrétien, L. Bonnet, R. Boulesteix, A. Maître, C. Sallé, and A. Brenier, "Influence of hot isostatic pressing on sintering trajectory and optical properties of transparent 
Nd:YAG ceramics,” J. Eur. Ceram. Soc., vol. 36, no. 8, pp. 2035-2042, Jul. 2016, doi: 10.1016/j.jeurceramsoc.2016.02.021.

[44] M. Cologna, V. Tyrpekl, M. Ernstberger, S. Stohr, and J. Somers, "Sub-micrometre grained $\mathrm{UO}_{2}$ pellets consolidated from sol gel beads using spark plasma sintering (SPS)," Ceram. Int., vol. 42, no. 6, pp. 6619-6623, May 2016, doi: 10.1016/j.ceramint.2015.12.172.

[45] V. Tyrpek1, M. Cologna, D. Robba, and J. Somers, "Sintering behaviour of nanocrystalline $\mathrm{ThO}_{2}$ powder using spark plasma sintering," J. Eur. Ceram. Soc., vol. 36, no. 3, pp. 767-772, Feb. 2016, doi: 10.1016/j.jeurceramsoc.2015.11.006.

[46] J.-F. Parisot and France, Eds., Nuclear fuels. Paris: Éditions le Moniteur : CEA, 2009.

[47] T. Zhang, P. Hing, H. Huang, and J. Kilner, "Sintering and grain growth of CoO-doped $\mathrm{CeO}_{2}$ ceramics," J. Eur. Ceram. Soc., vol. 22, no. 1, pp. 27-34, Jan. 2002, doi: 10.1016/S0955-2219(01)00240-0.

[48] W. W. Mullins and J. Viñals, "Scaling in linear bubble models of grain growth," Acta Metall. Mater., vol. 41, no. 5, pp. 1359-1367, May 1993, doi: 10.1016/09567151(93)90245-N.

[49] R. Podor, N. Clavier, J. Ravaux, L. Claparede, and N. Dacheux, "In Situ HT-ESEM Observation of $\mathrm{CeO}_{2}$ Grain Growth During Sintering," J. Am. Ceram. Soc., vol. 95, no. 11, pp. 3683-3690, 2012, doi: https://doi.org/10.1111/j.1551-2916.2012.05406.x.

[50] A. Maître, D. Beyssen, and R. Podor, "Modelling of the grain growth and the densification of $\mathrm{SnO}_{2}$-based ceramics," Ceram. Int., vol. 34, no. 1, pp. 27-35, Jan. 2008, doi: 10.1016/j.ceramint.2006.07.008.

[51] D. J. Srolovitz, M. P. Anderson, G. S. Grest, and P. S. Sahni, "Computer simulation of grain growth-III. Influence of a particle dispersion," Acta Metall., vol. 32, no. 9, pp. 1429-1438, Sep. 1984, doi: 10.1016/0001-6160(84)90089-0.

[52] J. R. MacEwan and J. Hayashi, "Grain growth in $\mathrm{UO}_{2}$, III. Some factors influencing equiaxed grain growth," Proc. Br. Ceram. Soc., vol. 7, p. 245, 1965.

[53] G. I. Nkou Bouala et al., "High-temperature electron microscopy study of $\mathrm{ThO}_{2}$ microspheres sintering," J. Eur. Ceram. Soc., vol. 37, no. 2, pp. 727-738, Feb. 2017, doi: 10.1016/j.jeurceramsoc.2016.08.029.

[54] L. Bourgeois, P. Dehaudt, C. Lemaignan, and J. P. Fredric, "Pore migration in $\mathrm{UO}_{2}$ and grain growth kinetics," J. Nucl. Mater., vol. 295, no. 1, pp. 73-82, May 2001, doi: 10.1016/S0022-3115(01)00502-5.

[55] F. Glodeanu, I. Furtuna, A. Paraschiv, and M. Paraschiv, "Grain growth in high density $\mathrm{UO}_{2}$, , J. Nucl. Mater., vol. 148, no. 3, pp. 351-352, 1987.

[56] R. Podor, V. Trillaud, G. I. N. Bouala, N. Dacheux, C. Ricolleau, and N. Clavier, "A multiscale in situ high temperature high resolution transmission electron microscopy study of $\mathrm{ThO}_{2}$ sintering," Nanoscale, vol. 13, no. 15, pp. 7362-7374, Apr. 2021, doi: 10.1039/D1NR00956G.

[57] S. Shukla, S. Seal, R. Vij, and S. Bandyopadhyay, "Reduced Activation Energy for Grain Growth in Nanocrystalline Yttria-Stabilized Zirconia," Nano Lett., vol. 3, no. 3, pp. 397-401, Mar. 2003, doi: 10.1021/n10259380.

[58] C. Wang, W. Huang, Y. Wang, Y. Cheng, B. Zou, X. Fan, J. Yang, X. Cao, "Synthesis of monodispersed $\mathrm{La}_{2} \mathrm{Ce}_{2} \mathrm{O}_{7}$ nanocrystals via hydrothermal method: A study of crystal growth and sintering behavior," Int. J. Refract. Met. Hard Mater., vol. 31, pp. 242-246, Mar. 2012, doi: 10.1016/j.ijrmhm.2011.12.002. 


\section{Supporting information}

Single crystals
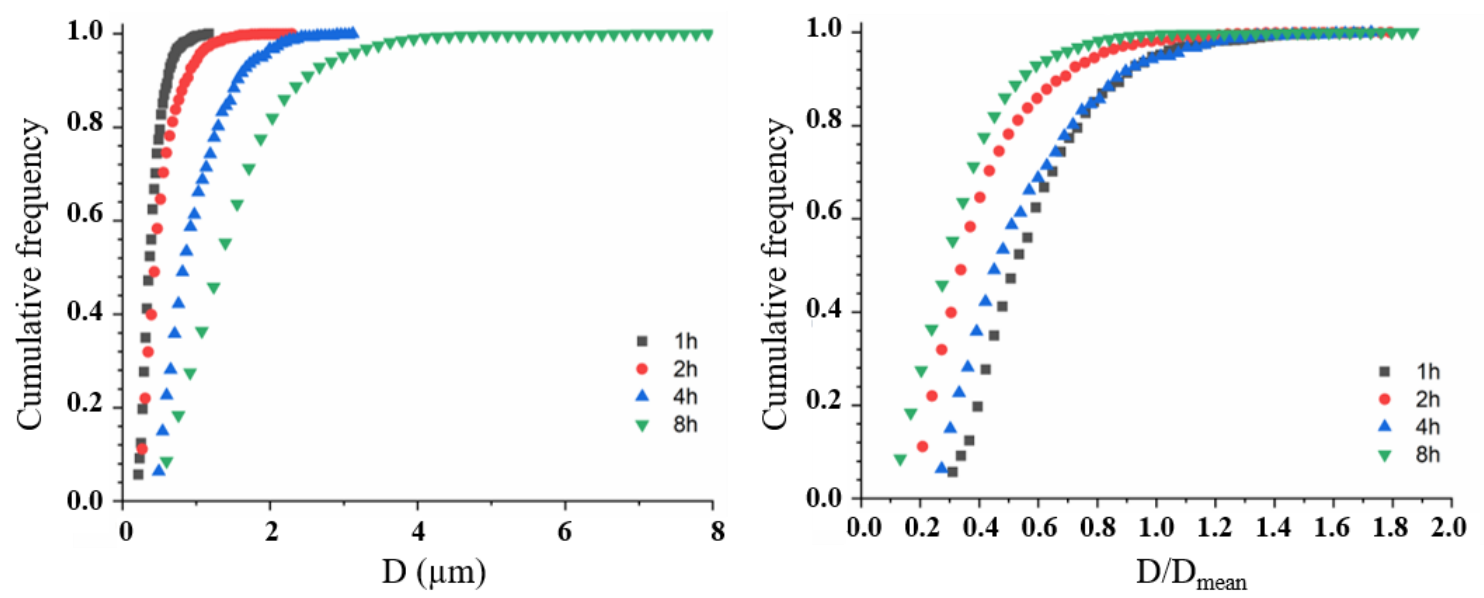

Microspheres
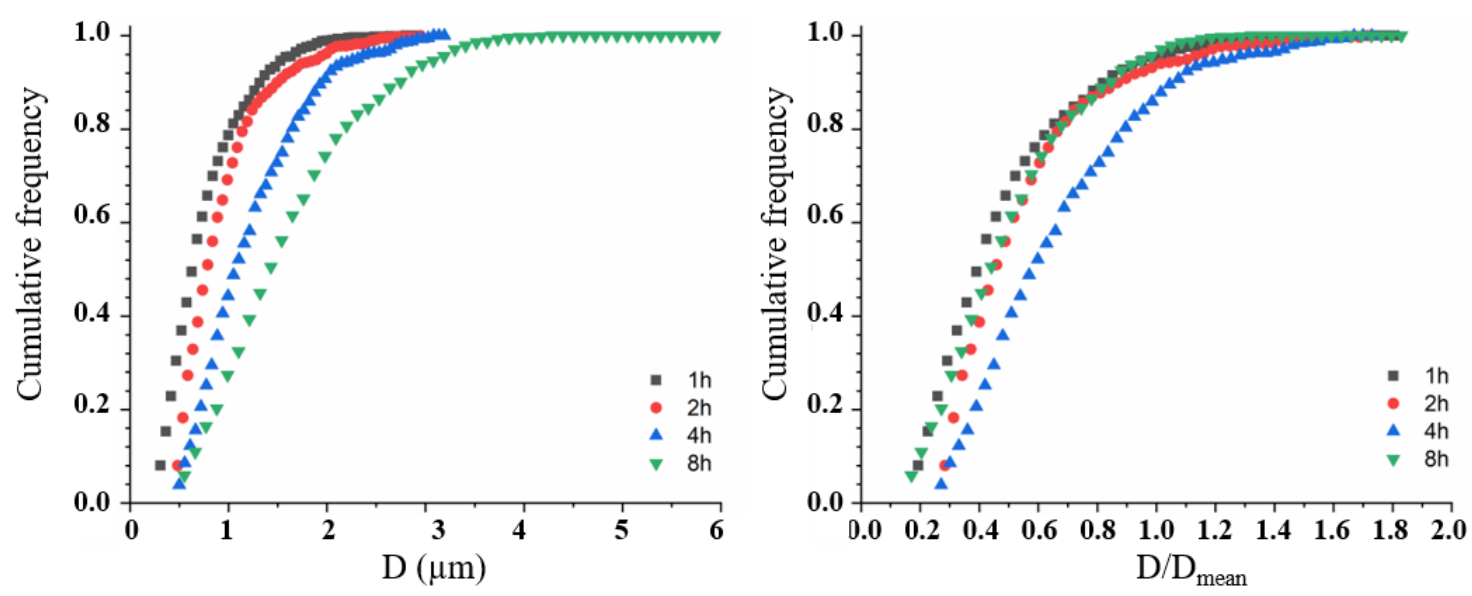

Figure S1. Representation of the particle size distribution within the pellets obtained from single crystals and microspheres at $1500^{\circ} \mathrm{C}$. 